Portland State University

PDXScholar

$5-24-2019$

\title{
Ecodistricts: Models for Sustainable Urban Development at the Neighborhood Scale
}

Jocelyn Reynolds

Portland State University

Follow this and additional works at: https://pdxscholar.library.pdx.edu/honorstheses

Let us know how access to this document benefits you.

\section{Recommended Citation}

Reynolds, Jocelyn, "Ecodistricts: Models for Sustainable Urban Development at the Neighborhood Scale" (2019). University Honors Theses. Paper 674.

https://doi.org/10.15760/honors.688

This Thesis is brought to you for free and open access. It has been accepted for inclusion in University Honors Theses by an authorized administrator of PDXScholar. Please contact us if we can make this document more accessible: pdxscholar@pdx.edu. 
Ecodistricts: Models for Sustainable Urban Development at the Neighborhood Scale

\section{Written by:}

Jocelyn Reynolds

\section{Thesis Adviser:}

Anna Goodman, Ph.D.

An undergraduate honors thesis submitted in partial fulfillment of the requirements for the degree of

\section{Bachelor of Science}

in

Architecture

and

University Honors

Portland State University 


\begin{abstract}
This thesis examines sustainable neighborhood design concepts called ecodistricts in the Pacific Northwest via a comparison of two case studies in order to determine patterns and best practices that have emerged over the past decade in the field of sustainable urban development. Through a practice-based research methodology, combined with a discourse analysis, The Village (LEED for Neighborhood Development) in Vancouver BC and Capitol Hill EcoDistrict in Seattle will be evaluated within the context of a growing regional focus on environmental design and urban sustainability. Both ecodistricts are regarded as key precedents of sustainable neighborhood models, but they differ in initial project objectives as well as final outcomes. Thus, in order to better inform urban designers during future related projects, it is important to understand how and why these two ecodistricts function and perform differently. Through an examination of publicity rhetoric, urban context and scale, and process of development, this thesis concludes by proposing a more incremental approach to ecodistrict implementation as opposed to rapid, large-scale, single-phase developments that leave little to no room for community engagement or future improvements. The conclusions of this research are intended to provide constructive recommendations for other cities and neighborhoods aspiring to form ecodistricts and pursue sustainability within their communities.
\end{abstract}




\section{Table of Contents}

1 - Abstract

3 - Introduction

9 - Lloyd EcoDistrict Context

13 - Case Study Background

18 - Research Methods

20 - Analysis

20 - Part One: Publicity and Discourse Material

38 - Part Two: Process of Development

45 - Part Three: Public Space as Social Infrastructure

50 - Part Four: Global Visionary but Locally Exclusionary

\section{3 - Conclusions}

54 - Recommendations for Lloyd EcoDistrict

\section{5 - Bibliography}

\section{9 - Appendix}




\section{Introduction}

As the world rapidly urbanizes, populations and natural resource consumption processes become more concentrated - increasing pressures on ecosystems, social infrastructures, transportation networks and energy/waste systems. It is especially critical to reduce these pressures in urban areas because, despite only covering 3 percent of the Earth's land, globally, cities are responsible for 60-80 percent of energy consumption and 75 percent of carbon emissions (United Nations, 2015). City municipalities are working to address this imbalance, and consequently, both the ecological and the social health of urban communities is becoming more of a priority. The architecture and planning fields are responding with proposals for eco-urbanism schemes and design models that not only achieve higher standards of environmental sustainability, defined by the UN as meeting the needs of the present without compromising the well-being of future generations (United Nations, 1987), but also provide frameworks for increased social equity, cultural resiliency, community health, and public engagement in the design process.

Private developers and public agencies/municipalities are partnering with community organizations to launch ambitious neighborhood-scale sustainability projects, often called ecodistricts, that range from creating pedestrian-friendly streetscapes lined with bioswales that manage stormwater to building high-rise apartments with energy efficient features, affordable housing units, and community amenities. Projects that operate at this scale with social and environmental justice related objectives fall under the category of "Sustainable Urban Development" (S.U.D.). The UN defines sustainable development as: 
"An integrated approach to urbanization based on a holistic view of its social development, economic development, environmental management (at the local, national and global levels) and governance components [that] entails the coordination of objectives and programmes among different city stakeholders (e.g., citizens, government and the business sector), as well as the development of linkages between and within socioeconomic sectors and activities. In economic terms, the integrated approach tries to improve synergies and efficiencies among activities such as public transportation, energy consumption, biodiversity and human health" (United Nations, 2013).

A key emphasis in the field of S.U.D. is the integration between economic, environmental and social sustainability. Specifically in the Pacific Northwest region, many cities have proposed aggressive action plans related to sustainable urban growth. These city-wide action plans often include incentive programs to promote healthier building practices and holistic neighborhood designs that include community infrastructure and restore natural ecologies. Some of the most innovative sustainable neighborhood design certification programs such as the Living Community Challenge, and EcoDistricts were born in the Pacific Northwest, and the region is now internationally recognized as a leader in ecological design and sustainable development.

This thesis focuses on the neighborhood scale of S.U.D., analyzing publicity material, urban context, the relationships between communities and the built environments they exist within, and project implementation processes within two ecodistrict case studies. The thesis conclusions ultimately propose that incremental change over time is a more ideal approach than rapid, large-scale development for communities who intend to progress towards more sustainable and livable neighborhoods. In this thesis, I will study The Village in Vancouver, British Columbia and the Capitol Hill EcoDistrict in Seattle, Washington. These case studies represent both global and regional trends towards S.U.D. While the generic publicity language 
conveys similar visions for both case studies, the actual social and environmental conditions that exist post-implementation are quite different, largely as a result of the true intentions and varying paces and scales of each project. Understanding why this gap between broadcast vision and actual outcome exists is crucial in order to identify key challenges and circumstances that may prevent neighborhood sustainability initiatives from being implemented to the best case scenario.

Looking broadly at these two ecodistrict case studies, it is very interesting that their final outcomes differ so greatly despite being born out of very similar regional circumstances and societal ideologies. Firstly, both Vancouver BC and Seattle are pillar cities for the Pacific Northwest's brand of green design and progressive social agendas. When looking at the climate in both cities regarding S.U.D. prior to the launch of the two ecodistrict projects, there was similar support from many different stakeholder groups, but especially from the public sector. Both the City of Vancouver and the City of Seattle's municipalities demonstrated desires to see more ecodistrict-type developments, and enacted various policies to help facilitate such projects.

The first example of this occurring involves the site that The Village in Vancouver was built on. The Village was built on a large plot of formerly industrial brownfield land that the City had been looking to redevelop for over a decade. The partnership was mutually beneficial, as The Village development team received City support via policy incentives and financial backing, while the City used the project as both a physical and a metaphorical platform to waive its Sustainable City flag for all the world to see. Vancouver began ascending into this global spotlight in 2003 when Canada decided to promote the construction of LEED certified buildings 
as a national best practice. In 2018, Canada was ranked second after China in the U.S. Green Building Council's annual Top 10 Countries and Regions for LEED certified projects, with 4,025 certified projects at the time (Canada Green Building Council, 2018). US Green Building Council(USGBC) CEO and founding chair, Rick Fedrizzi praised Canada for its achievements, saying, "At a time when the world needs real leadership to solve the problems facing us all, Canadian business leaders, policymakers and consumers have turned to LEED to show the international community what we can do at the local level to promote real, substantive change" (Crawford, 2017).

The City of Vancouver is also commendable for taking their own initiative to write policies aimed at creating a more sustainable future. In July 2011, the City Council approved an action plan titled: "Vancouver 2020 A Bright Green Future: An Action Plan for Becoming the World's Greenest City By 2020" (Boyd, 2011). This plan was spearheaded by former Mayor Gregor Robertson's 'Greenest City Action Team' in 2009. The intentions of this Action Plan are multifaceted. The vision is to build a strong local economy with vibrant and inclusive neighborhoods in order to keep Vancouver on the "leading edge of sustainability" as it becomes "the greenest city in the world" and an "internationally recognized city that meets the needs of generations to come" (City of Vancouver, 2011). Nine years later, Vancouver is witnessing their visions come to fruition, receiving numerous international awards for livability and green city indicators that are conveniently compiled on the official Tourism Vancouver website. In 2014, the Global Green Economy Index ranked Vancouver as the Fourth Greenest City in the World based on its performance in leadership and climate change, efficiency sectors, markets and investment and environment and natural capital (Metro Vancouver). In 2016, the Arcadis 
Sustainable Cities Index ranked Vancouver as the Most Sustainable City in North America and the 23rd city globally based on the people-planet-profit model (Metro Vancouver). In 2017, it was ranked by the World Economic Forum as the 'Greenest' City in the World based on its tree canopy, as well as the Most Livable City in North America and the fifth in the world by Mercer's annual livability survey (Metro Vancouver). In 2017, Vancouver was ranked the 3rd Most Liveable City in the World by the Economist Intelligence Unit's annual Global Liveability Report that considers factors such as healthcare, culture, environment, education and infrastructure (Metro Vancouver). The city was recently listed as one of the Global Top 100 Sustainable Destinations for 2018 due to its dedication to sustainable tourism programs and again ranked the Most Livable City in North America by Mercer (Metro Vancouver).

Idea seeds for a Capitol Hill EcoDistrict in Seattle were also planted during a time where the political climate in Seattle, led by Mayor Greg Nickels, very much favored green urbanism movements and sustainable city ideologies. In January 2005, Seattle's Department of Planning and Development published their new Comprehensive Plan titled: Towards a Sustainable Seattle (City of Seattle, 2005). After conducting a growth and equity analysis in 2016, the City updated the Plan to include more protection for marginalized populations who are at a higher risk for displacement caused by development. This updated Seattle 2035 Plan is meant to guide decision-making regarding development for the next twenty years. This marks a big milestone for Seattle and represents their commitment to working towards a more holistically healthy city that takes into account ecological health as well as community health of its residents. Thus, both The Village and Capitol Hill EcoDistrict had the wind at their sails in terms of City support as they went through Design Review and Construction project phases.

Other external factors that created similar incubator conditions for both projects include economic growth, environmental patterns, population size, and projected population growth. As 
ecodistrict projects are very expensive and require a high level of cross-disciplinary collaboration, funding, and planning, upward economic growth in Vancouver and Seattle was a major benefit. Environmentally, both coastal cities are in the same bioregion, with similar rainfall patterns and landscapes, thus pointing the ecological design teams towards similar strategies for managing stormwater or restoring natural habitats. Population-wise, the estimated population of Vancouver proper in 2016 was 631,486 (Statistics Canada, 2017), while Seattle proper's population was estimated to be 686,800 in 2016 (City of Seattle, 2016). It is important to note that $74 \%$ of people in the Metropolitan Vancouver area live outside the city proper (Metro Vancouver, 2015). Vancouver Metro estimates that Vancouver proper will grow by 155,000 by 2041(Metro Vancouver, 2015) while Seattle expects to increase by 120,000 people by 2036 (City of Seattle, 2016). Similar predictions for growth play a key role in urban planning policies as both cities anticipate increased density in urban core areas. 


\section{Lloyd EcoDistrict Context}

While Vancouver and Seattle are nurturing their respective ecodistricts along, Portland, Oregon has been developing its own Lloyd EcoDistrict in the heart of the central eastside. As the pilot project for the EcoDistricts organization's sustainable neighborhood framework and its first certified project in 2011, the Lloyd EcoDistrict team has made some unprecedented strides in the field of S.U.D. (EcoDistricts, 2017). Born after The Village and before Capitol Hill's EcoDistrict, Lloyd is centrally situated within the current eco-urbanism discourse. As all contemporary ecodistrict projects are inherently in dialogue with each other and the larger field of S.U.D., Vancouver's Village and Seattle's Capitol Hill EcoDistrict both serve as valuable precedents for the Lloyd team to draw inspiration from. In Phase 1 of Lloyd EcoDistrict's development, three LEED Platinum mid-rise luxury apartment buildings were constructed, with ground floor retail space. Streetcar lines, light rail MAX lines, TriMet bus routes, protected bike lanes, pedestrian-only streets, a public plaza, a pollinator corridor, district-wide wastewater treatment system, ecoroofs, neighborhood bike storage and a bike shop with showers, were just a few of the many key features added to the neighborhood. Phase One primarily consisted of the intense and isolated development of one superblock: Hassalo on 8th. This development served as the catalyst and continues to be the heartbeat of Lloyd EcoDistrict, which extends beyond Hassalo.

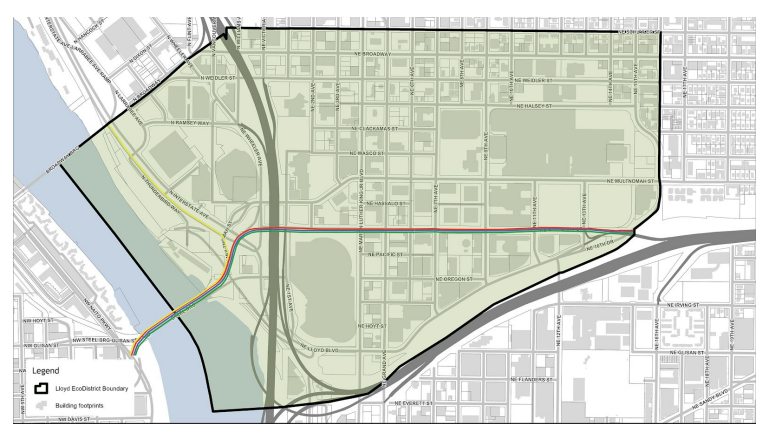

Image: Lloyd EcoDistrict Map

Source: City of Portland BPS

As Lloyd envisions more growth in its EcoDistrict, American Assets Trust and GBD Architects have a huge opportunity to make informed design decisions based on other ecodistrict precedents. The project team is now at a crossroads as they look towards Phase 2 of development and beyond. Is the isolated rapid superblock development method that was employed during the Hassalo on 8th development the ideal method moving forward? Will this method stimulate the community cohesion element that is a necessary component to any sustainable urban development? With the Lloyd EcoDistrict's stated goals to "Promote high-density mixed-use development and supportive amenities in the core" and "Encourage sustainable development including green buildings, green infrastructure and habitat enhancement" (City of Portland BPS), the case studies presented in this thesis will provide valuable suggestions for the Lloyd EcoDistrict moving forward. 


\section{Key Terms and Concepts}

There is a growing number of bureaucratic certifications that, collectively, demonstrate a global trend towards formalizing and promoting S.U.D. Not only do these certifications aim to enrich the ecological health and lives of those who inhabit the buildings or open spaces within the developments, but they also elevate a city or firm's status as forward-thinking and environmentally conscious on the global stage. The case studies examined in this thesis are certified as either a LEED for Neighborhood Development (LEED ND) project or as an EcoDistrict. LEED ND was born out of its older parent certification, LEED, which stands for Leadership in Energy and Environmental Design. LEED is one of the most well-known and widely-adopted international green building rating systems. Created in 2000 by the US Green Building Council (USGBC), it is a 'green certification program for building design, construction, operations and maintenance' intended to 'promote sustainability-focused practices in the building industry' (USGBC, nd). LEED awards credits to projects that incorporate elements such as energy efficient lighting fixtures or responsibly-sourced building materials. Based on the number of credits that a projects earns, it may achieve a Certified, Silver, Gold or Platinum rating level. The original LEED program certified individual buildings based on a highly specific list of criteria, and primarily focused on aspects of the physical form that affect the natural environment.

As a response to criticism concerning LEED's lack of emphasis on addressing social equity, community health, and cohesive neighborhood livability, coupled with a growing consensus within the architecture and planning field that the district-scale is the most effective 
scale to operate at in terms of achieving greater sustainability within the built environment, the USGBC created LEED for Neighborhood Development (LEED ND) in May 2009 (USGBC LEED-ND 2013). LEED ND is for projects operating at a much larger scale than a single building or block, and promotes innovative land use patterns by encouraging design teams to integrate district-scale systems such as energy loops or wastewater treatment that connect the various buildings and open spaces together. Typically, LEED ND projects are mixed-use developments with both residential and non-residential uses. This rating system takes into account not just the buildings within the project, but also features designed for the public realm and wildlife habitat. Its four rating categories are: smart location and linkage, neighborhood pattern and design, green infrastructure and buildings, and innovation and design process (Congress for the New Urbanism, nd). The emergence of LEED ND and other similar certification programs mark a shift in the priorities of planners and architects and represents an attempt to recalibrate the mentality of the design community towards one that places greater value on holistically sustainable neighborhoods.

One certification program that goes beyond LEED ND in addressing district-scale S.U.D. is called EcoDistricts, which was founded in Portland, Oregon in 2013 (EcoDistricts 2018). While LEED and even LEED ND focus primarily on sustainability building practices during the construction phase of projects, EcoDistricts go beyond this by encouraging project teams to implement features that foster healthy community development of those that live or work in the EcoDistrict once the project's construction is completed. This is a long-term focus, and the full fruits of these intentions may not be seen for ten to twenty years after a neighborhood gets its EcoDistrict certification. The EcoDistrict Protocol is "a rigorous, 
sustainable urban development framework for achieving people-centered, economically vibrant neighborhood- and district-scale sustainability"(EcoDistricts Protocol 2018) that requires projects to focus on three main Imperatives: Equity, Resilience, and Climate Protection. Additionally, projects must meet twenty objectives that range from preserving and celebrating historic and culturally significant places to creating high quality and engaging public spaces to increasing access to public transportation to managing rainwater through a district system.

Beyond the slight differences in S.U.D. certifications, The Village in Vancouver and Seattle's Capitol Hill EcoDistrict also differ in development type and processes as well as varying project scopes and pre-existing site contexts. This all resulted in starkly contrasting final outcomes in each ecodistrict. The Village was a blank slate project, where the developer and design team have nearly autonomous control over an entirely undeveloped plot of land and develops it all at once. Thus, all of the residential, commercial, public open spaces, green spaces, underground infrastructure, pedestrian and bike paths, and transit streets were constructed simultaneously. The Capitol Hill EcoDistrict is being developed within the pre-existing context of the densest residential neighborhood in Seattle, meaning that the project team is pursuing urban infill strategies, where smaller pieces of underdeveloped land or underutilized spaces are revitalized incrementally. The National League of Cities defines urban infill as "new development that is sited on vacant or undeveloped land within an existing community, and that is enclosed by other types of development...filling in the gaps" (National League of Cities, 2017). This process does not have a finite finish line and can keep occuring for forever theoretically. 


\section{Case Study Background: The Village in Vancouver, British Columbia}
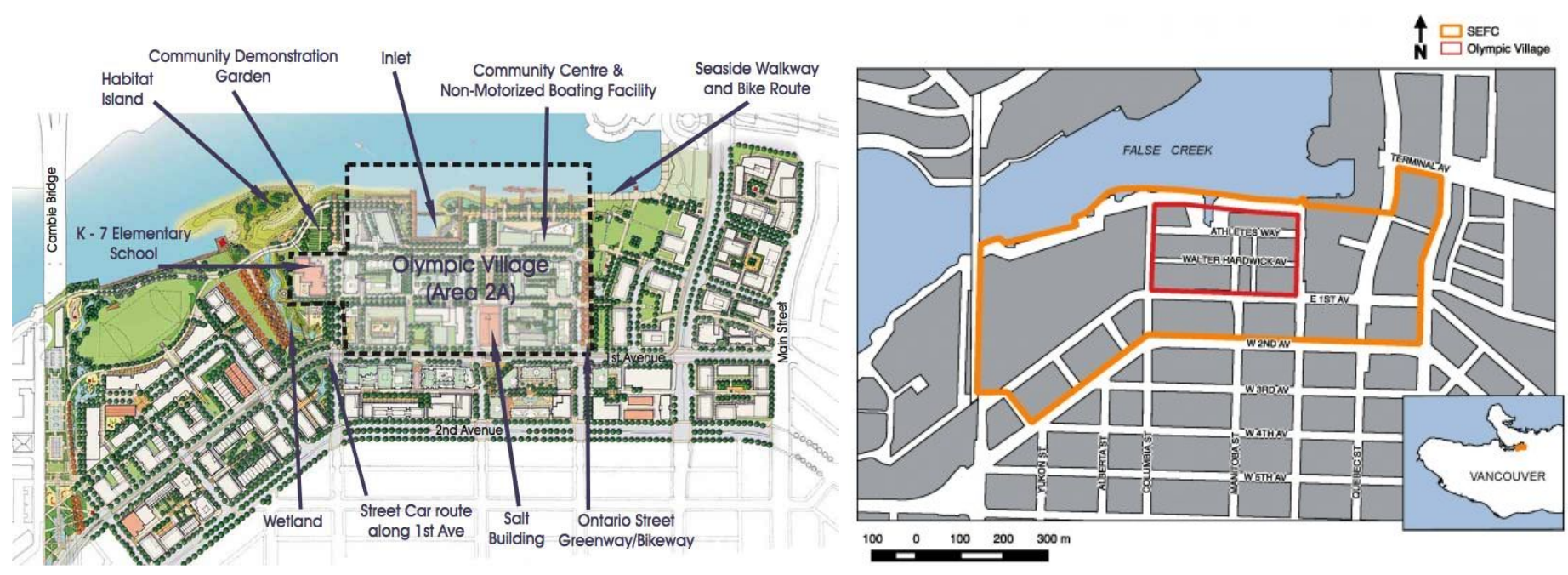

Image 1: Vancouver Olympic/Paralympic Village

Source: Green Building Brain, nd

Image 2: Map of SEFC Area and Olympic Village Source: Lisa M Westerhoff, 2016

Although developed on an isolated plot of land, the design and project implementation of The Village in Vancouver was greatly influenced by external factors, namely the City's sustainability agenda and the constraints of the fast-approaching 2010 Winter Olympics slated to be held in Vancouver. The City had been looking to redevelop what they call the Southeast False Creek (SEFC) Area from an industrial brownfield into an 80 acre sustainable urban neighborhood since 1990 (City of Vancouver, 1999), adopting a Southeast False Creek Policy Statement in 1999 to facilitate the process. Due to its proximity to the central downtown business district, the site had great economic promise. Many city-wide initiatives such as 'Clouds of Change' (City of Vancouver, 1990) and 'Visions, Tools, Targets' were created to generate enough support to launch such a large project like The Village (Nfaziol, 2015). The Village on False Creek, originally called Millennium Water, became the pilot project for the SEFC area, and was the first phase of the larger development plan. The Village is the largest 
single-phase development in Canada (Kher, 2010), spanning the equivalent of fourteen blocks. All of the soil had to be remediated before construction began. The neighborhood scale development consists of sixteen residential buildings built atop seven city blocks. In total, 1,100 condo units were built, equaling 6.3 million square feet of residential space (GGLO, 2012, p. 4). All sixteen buildings are LEED Gold Certified, but the neighborhood itself is LEED Platinum Certified for Neighborhood Development (LEED-ND). It was originally built to house 2,800 athletes and officials during the 2010 Winter Olympics (City of Vancouver, 2010). The project was under severe time constraints, as all of the units had to be ready before the Games began. This deadline helps provide context to possibly explain why some seemingly unwise decisions were made along the way, particularly involving financing and protecting social equity interests. Following the Games, the units were converted into luxury condos that sold for a premium price.

Public-private partnerships played a crucial role in the project, beginning in 1990 when the City began priming the area for development, and going all the way to the sale of the final units post-Games. Due to the sheer magnitude of the undertaking, six architecture firms were employed: Merrick Architecture; Gomberoff, Bell, Lyon Architects; Arthur Erikson, Nick Milkovich Architects; Walter Francl Architecture and IBI Group. The campus-like development features many advance green features such as district energy utility and waste heat recovery systems as well as rainwater harvesting and stormwater management regional best practices. The project's financing was partially funded by the City and partially by the private sector, mainly Millennium Development Corporation. However, on November 17, 2010, the project was put into receivership to the City as Millennium Development owed over $\$ 740$ million. 
Thus, the complex's name was changed to The Village on False Creek (Mackin, 2014). At this point, the City had to manage the sale of the remaining units. Despite The Village development ending on a sour note, the silver lining is that this project was actually the catalyst for Rob Bennett and Tom Osdoba, who were involved in the project, to found the Portland-based EcoDistricts organization (EcoDistricts, 2018). This EcoDistricts framework was then applied in Seattle's Capitol Hill neighborhood to launch the Capitol Hill EcoDistrict, which is the second case study in this thesis.

In terms of ecological site context, one third of The Village is bounded by the south-east shore of an inlet, hence the name Southeast False Creek, and a habitat restoration island that jets out from Hinge Park, the largest green space in the neighborhood. Vancouver wraps around this bay, so The Village looks across the bay at the heart of downtown Vancouver proper.

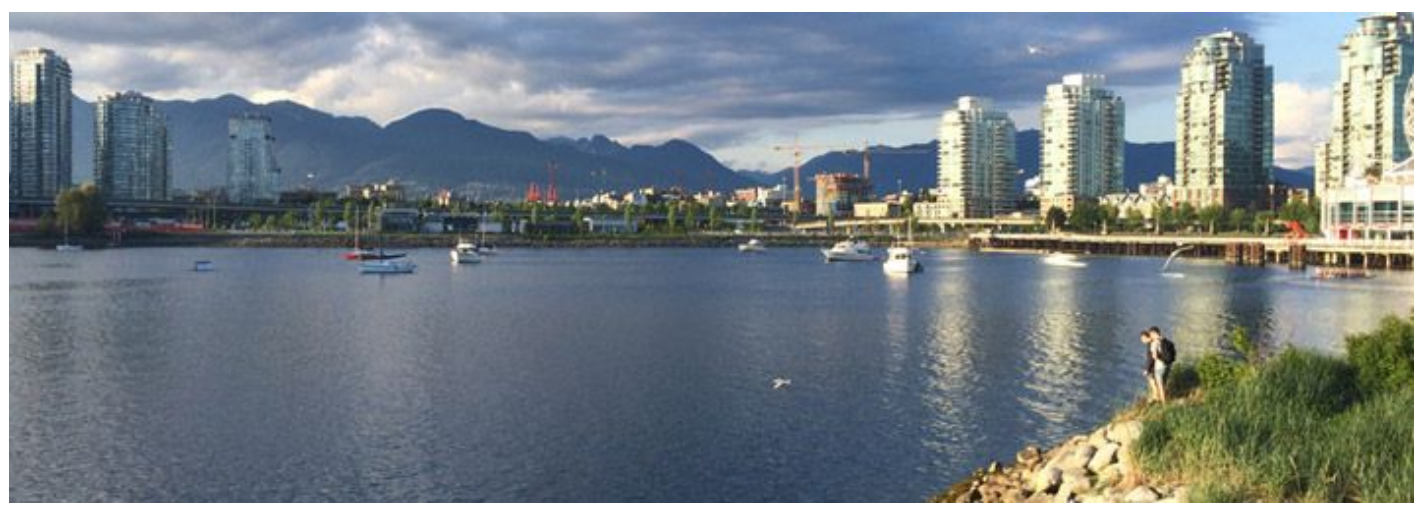

Image: View from False Creek Olympic Village

Source: City of Vancouver Board of Parks and Recreation 


\section{Case Study Background: Capitol Hill EcoDistrict in Seattle, Washington}

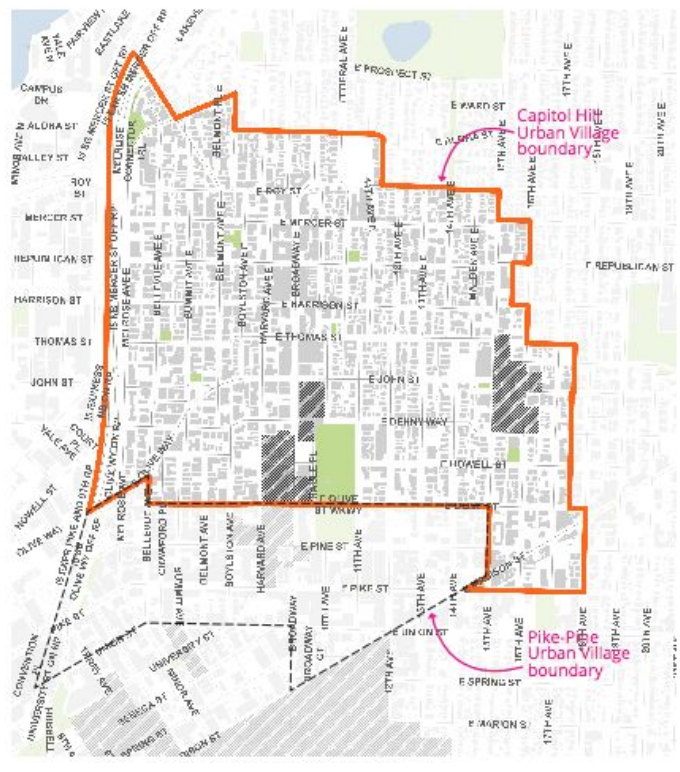

Image 1: Capitol Hill Neighborhood Design Guidelines Boundary Source: City of Seattle, The Urbanist

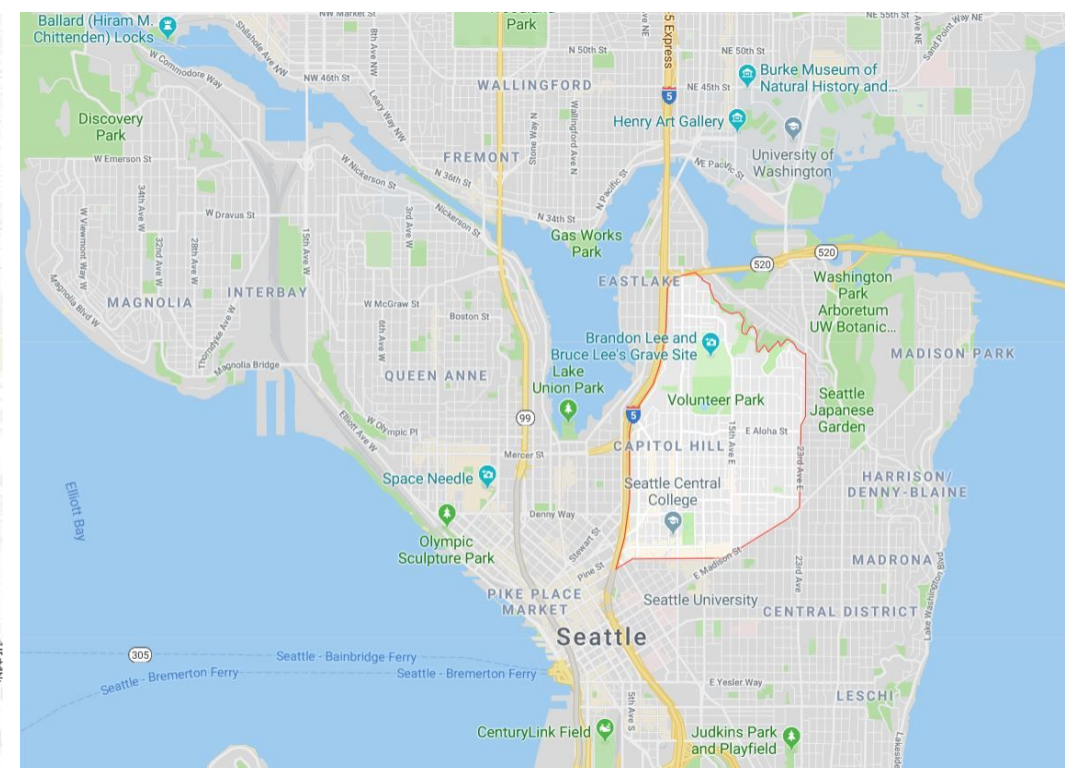

Image 2: Capitol Hill Neighborhood Outline Source: Google Maps

The idea for a Capitol Hill EcoDistrict emerged in March 2011 when Capitol Hill Housing $(\mathrm{CHH})$, a public development authority for affordable housing, began envisioning the neighborhood that they serve as one where residents and businesses come together to work towards improving the livability and ecological health of their community. After receiving a grant from the Bullitt Foundation to conduct a feasibility study and write a proposal report, CHH pitched the idea of an EcoDistrict to the City of Seattle. CHH worked with GGLO, a Seattle-based urban design firm, for one year to research the process and determine the feasibility of forming an EcoDistrict in the Capitol Hill neighborhood. CHH has continued to be the primary backbone of the EcoDistrict and the collective voice for the greater neighborhood community. Since becoming a recognized EcoDistrict in 2012, the steering committee, city staff, residents, and community partners have spearheaded numerous successful neighborhood enriching programs and projects. 
The Capitol Hill EcoDistrict is a unique case study because of the neighborhood's dense pre-existing conditions consisting mostly of mid-rise residential apartment buildings, which led to a very different framework for development. The Capitol Hill neighborhood dates back to 1900 and is now Seattle's densest residential neighborhood with minimal undeveloped land remaining in the area. Thus, rather than take the blank slate development approach that Millenium Development Corp. was able to take in Vancouver, the team had to think innovatively about smaller projects that would fit into the existing urban fabric and still improve the area without having to remove a pre-existing structure or amenity. The Capitol Hill EcoDistrict organization focuses more on social outreach programs, community engagement and active participation on land use review committees to help guide physical developments in the neighborhood that are led by other entities rather than developing large projects themselves. Capitol Hill EcoDistrict's neighborhood sustainability projects are typically urban infill projects, which are carried out incrementally over time, allowing the EcoDistrict team to focus on one or two projects at a time without being overwhelmed. Examples of urban infill projects could include adding a bioswale along two blocks of one street or working with two adjacent building owners to share parking rights in order to address the parking crisis in the area. This park-sharing initiative was so successful that the City of Seattle recently adopted it as a City-wide policy.

While The Village's population has a median age of 37 (Vancouver Magazine n.d.), Capitol Hill EcoDistrict's median age of residents is 32. Very few families with children live in either neighborhood. More than half of Capitol Hill EcoDistrict's residents hold a bachelor's degree or beyond (Williams and Kendle, 2019). Visit Seattle describes Capitol Hill as "The 
unofficial center of Seattle's LGBTQ community, this lively neighborhood buzzes with some of the city's hippest restaurants, bars, and boutiques (Boynton, n.d.). The EcoDistrict team is very committed to preserving the culture of the neighborhood. When doing outreach and community development work, the team has taken a progressive step to engage not just homeowners but also renters in the neighborhood. This EcoDistrict's social equity focus is one of the primary differences that set it apart from The Village.

\section{Methods and Theoretical Frameworks}

In general, the analysis of evidence in this thesis is conducted in accordance with a practice-based research methodology specific to the architecture and urban planning fields, and is less built upon theoretical frameworks of thinking. However, specific sections of the analysis will apply other methods or theories. When evaluating the written and graphic language of publicity material pertaining to the creation and formalization of both ecodistrict case studies, I will apply the discourse analysis method. ${ }^{1}$ This technique examines vocabulary, syntax, and metaphors used in communication outlets like mission statements or quotes from stakeholders, and then compares these findings against that of other similar projects within that specific discussion. In this instance, I will be comparing and connecting the language employed during the formation of The Village to that for Capitol Hill EcoDistrict, as both of these case studies were born during the same era and specific discourse within the field of sustainable urban design at the neighborhood level. Lastly, there is an overarching 'social practice' that is created

\footnotetext{
1 "A social practice which constructs social identities, social relations and the knowledge and meaning systems of the social world ... [which] both reflects and produces the ideas and assumptions relating to the ways in which personal identities, social relations, and knowledge systems are constituted through social practice" (Nielson and Nørreklit, 2009; p. 204-205).

http://www.emeraldgrouppublishing.com/research/guides/methods/discourse_analysis.htm
} 
through the collective construction of this discourse rhetoric as more and more ecodistricts emerge onto the global stage. Identifying these larger practices can be very telling of the societal moment and thought movements/ideologies/dominant value systems within the development realm ecodistricts are being born during.

Next, I will discuss the actualization of this discourse as it manifested itself in both the built environment and social infrastructures in each ecodistrict using practice-specific evaluation metrics. I will draw evidence from personal site observations noted during my site visits to both ecodistricts in March 2019. While I only observed each ecodistrict for one day, and I was not an "insider" in the areas, I still consider these observations valid and relevant to the discussion in this thesis.

I will also apply ideas of social infrastructure to my evaluation of the current existing conditions in both ecodistricts. The practice-based analysis sections of this thesis focus primarily on the public spaces within each ecodistrict. Public space is a key form of social infrastructure, which can be defined as the physical spaces and organizations that support the development of social capital by influencing the interactions and behavior of people engaging in such spaces or with such organizations. Social infrastructure typically refers to the physical features of the built environment that support community development and neighborhood cohesion. However, social infrastructure can also exist in the form of engagement programs that foster positive relationships between community members, such as residents or businesses. In this form, it becomes a generative community framework that can evolve with the neighborhood and its social ecology. 


\section{Part One: Discourse Analysis of Publicity Materials}

In this section, two modes of discourse communication are examined to provide insight into the intentions, value systems, and visions held by the two project teams while they were initially creating concepts for The Village and Capitol Hill EcoDistrict. First, textual material, such as city policy statements and design guidelines, mission statements from the ecodistrict organizations, and listed project goals are presented. This rhetoric is used to determine the collective language employed by each ecodistrict as it branded itself and publicized its work. Second, the graphic promotional language, published in the initial envisioning and design phases of the ecodistricts, is analyzed and compared against the written discourse. Additionally, this section looks at how each project is communicated to local audiences and a broader global audience. The ways that the project teams describe and visualize their neighborhood concepts also speak to larger patterns of social thinking and values. This discourse evidence will later be compared against the projects' physical manifestations and used to better understand the implementation processes.

The ecodistricts' outcomes and implementation processes differ greatly from each other, partially due to the inherent understanding and application of the term 'neighborhood.' While the contemporary general opinion in the field of S.U.D. is that the neighborhood is the most effective scale to operate on (GGLO, 2012, p. 1), there is a wide range within this scale that can cause two 'neighborhood' projects to look and feel very different from each other. For instance, two neighborhood-scale projects could be built atop equal plots sizes of land, but have different densities in terms of the ratio of open space to developed space. Or, both schemes could be built on equal plots of land and have the same gross building square footages, but they could have 
very different uses. One could be primarily commercial and office spaces, while the other could be primarily residential apartments with ground floor retail. In the Capitol Hill EcoDistrict proposal report, the director explains that:

"It is widely recognized that the prospects for sustainable development are greatly improved when design is approached from a systems perspective. In the case of the built environment, this means thinking beyond a single, isolated building, and tapping into synergies with the surrounding buildings, infrastructure, and community. An EcoDistrict is a conceptual framework designed to facilitate this scale jump. To that end, an EcoDistrict can entail a wide variety of sustainability strategies implemented at scales ranging from a few buildings to entire neighborhoods" (GGLO, 2012, p. 1)

The Capitol Hill EcoDistrict team's understanding of the ranging neighborhood scale played a major role in influencing how they wrote their strategies to target their various performance goals, some of which applied to the entire district, while others only applied to a single block of sidewalk. As The Village development had a very distinct physical boundary line inside which the entire project was confined by, its design team had a different understanding of the term 'neighborhood,' so most of its features extend throughout the entire complex, whether they be bike paths or rainwater harvesting systems.

\section{Discourse Analysis - Written Rhetoric Refer to Appendix A.}

Like any formal entity, the ecodistricts studied in this thesis both have mission statements, and like any contemporary development, both operate within city-written design guidelines. While mission statements are meant to hold a team personally accountable and city codes are put in place to ensure that projects adhere to larger citywide visions, both greatly affected the decision-making processes during the formation of The Village and Capitol Hill EcoDistrict. Some of the mission statements and objectives were written during very early 
project phases when the teams were still exploring the feasibility of creating ecodistricts. The City of Vancouver's design guidelines for the site that The Village was developed on were first originally written in 1990 when the city began thinking about redeveloping the large swath of industrial brownfields. They have since been updated, but it is worth noting that some policies have been in place for over a decade yet have still had profound impacts on ecodistrict development. The City of Seattle just ratified new design guidelines for the Capitol Hill neighborhood in April 2019, which were largely based on the objectives previously generated by the EcoDistrict team. Thus, both city policies and ecodistrict internal policies can affect each other reciprocally.

\section{City Policy Statements and Design Guidelines}

Ideas for a development like The Village have been percolating through Vancouver's layers of government for decades. In 1990, The City began drafting a comprehensive set of development guidelines in a document called the Southeast False Creek (SEFC) Policy Statement meant to facilitate redevelopment of the post-industrial brownfield SEFC area into a sustainable neighborhood. This policy statement includes fifteen Core Project Principles. These guiding principles detail the City's long-term visions for the SEFC redevelopment district, which applied to The Village and continue to apply to any other future development that occurs in the area. The Village was the pilot project for these City-written Principles. Some of the most relevant core project principles are: to implement sustainable urban development, to be positive stewards of ecosystem health, to promote economic and cultural vitality, to create a livable neighborhood that protects housing diversity and equity, to remain accountable to the public, and ultimately to create a 'complete community where residents can live, work, play and learn 
within a convenient walking, cycling or transit-riding distance' (Nfaziol, 2015). The Livability Principle is further explained as aiming to "enhance the social and natural environment by creating a walkable, safe and green neighborhood.” The Accountability Principle closely relates to social sustainability goals by aiming to "promote accountability by monitoring impacts using post-occupancy studies and community consultation." The key verbs used in these principles are: implement, steward, promote, create, protect, enhance, and monitor. For the most part, these verbs have positive connotations of safety and wellbeing. Slightly less wholesome intentions are revealed in Vancouver's city-wide action plans. Goal number one of Vancouver's 2020 Greenest City Action Plan is to "Secure Vancouver's international reputation as a mecca of green enterprise" (City of Vancouver, 2011, p. 11). This action plan is also referred to as Vancouver 2020 A Bright Green Future, in which city officials write that "Becoming the greenest city is more than an environmental objective: it's also a savvy economic strategy, for it will offer a competitive advantage in attracting highly mobile investment dollars, businesses, entrepreneurs, and talented workers" (Boyd, 2011, p. 11).

Just as The Village operates within Vancouver's larger development framework for the SEFC Area, Capitol Hill EcoDistrict projects are also inherently intertwined with City of Seattle policymaking. On April 16, 2019 (Assefa, 2019), Seattle's Mayor and team of city planners finished updating the 2005 version of the Capitol Hill Neighborhood Design Guidelines and sent the document to City Council for review and approval. The EcoDistrict team, along with Capitol Hill Housing, helped write these guidelines and engage community stakeholders throughout the process, so much of the language used in this document echo the narrative on the EcoDistrict's website and in their framework reports. Furthermore, there are many similarities 
between Vancouver's visions for The Village and Seattle's collective aspirations for their Capitol Hill EcoDistrict. Consequently, there is a great deal of overlap in the discourse language used to publicize both projects. For example, one of the Core Project Principles in Vancouver's SEFC Policy Statement is to promote economic and cultural vitality. The City of Seattle wrote that "The new design guidelines will guide future development within the Capitol Hill Urban Center Village to maintain and further develop healthy, diverse, and vibrant areas" (Assefa, 2019). Likewise, part of Capitol Hill EcoDistrict's primary mission is to promote a culturally vibrant neighborhood (see Appendix A). Public statements like these play a key role in developing the urban sustainability narrative that the Pacific Northwest Region is renowned for.

\section{Primary Mission Statements Refer to Appendix A.}

Another key form of publicity material is the primary mission statement, usually generated by the ecodistrict team in an effort to brand their project as well as guide neighborhood decision-making. As previously mentioned, The Village was the pilot project for a larger, City-led redevelopment plan, so most of its target goals and focuses were written by the City of Vancouver. The mission statement that most closely speaks to The Village is the one written by the City about the entire Southeast False Creek area redevelopment:

"While maintaining heritage ties to the past, SEFC is being planned as a model sustainable development based on environmental, social and economic principles where people will live, work, plan, and learn."

- (City of Vancouver, 1999)

The 'heritage ties' phrase is in reference to the cultures of Indigenous peoples that lived in the region before the British colonized the area as well as more recent industrial land use. The term 
'model' is multidimensional here- firstly reminding that The Village is intended to be the precedent for the larger SEFC development, and secondly pronouncing that the entire SEFC area will eventually become an internationally renowned example of sustainable neighborhood development. As Vancouver is an international hub for many sectors like finance and investment, and the Winter Olympics were set to take place in 2010, the project team knew that an international audience would be watching this development through all phases.

Because The Village was privy to following the City's SEFC Core Principles, the development team did not have to generate their own mission statements or publish explicit sustainability-related deliverables. As a result, there is a distinct lack of written publicity material from the actual project team. I argue that this transitively also led to a lack of accountability and indifference towards sustainability goals, specifically related to providing affordable housing and ensuring quality of construction. There is also a distinct lack of cohesion in terms of marketing for and sense of community in The Village. LEED for Neighborhood Developments are supposed to prioritize district unity, both in terms of systems and social networks, but The Village does not even have its own website. Individual luxury condominiums within The Village are being sold for millions all over various real estate websites, some of which highlight the sustainability features while others don't acknowledge them at all.

On the other hand, Capitol Hill EcoDistrict has very well-defined goals and objectives, largely as a result from the support they received from the EcoDistrict organization staff in Portland who guided the development of these goals. Capitol Hill EcoDistrict's primary mission statement, listed on the homepage of their website, is to be "A community-driven effort that promotes a socially equitable, environmentally resilient and culturally vibrant neighborhood" 
(Capitol Hill EcoDistrict, 2012). A very similar statement is listed at the bottom ribbon of the website, stating that the EcoDistrict is "A community-driven effort to make our neighborhood a national model for environmental sustainability and community health." There are obvious similarities between the two statements, however, the first seems to be more internally focused, while the second one seems to be more about projecting the good intentions of the EcoDistrict to a larger, broader audience. Both statements begin by emphasizing that this district-scale organization is a grassroots effort built from the ground up by real people who actually live or work in the neighborhood and who are invested in its vitality. The second statement even uses the word 'our' to establish a collective ownership of and citizen efficacy within Capitol Hill. It is also worth noting that the term 'effort' is used rather than a term such as 'organization' or 'coalition' which both have slightly exclusionary connotations. Effort, on the other hand, is very universal and inclusionary because anyone in the community can theoretically contribute to the effort of improving the Capitol Hill neighborhood.

While both of Capitol Hill EcoDistrict's mission statements convey a desire to work towards greater neighborhood sustainability, they seem to speak to slightly different audiences. The first statement feels to be speaking more to a local audience, letting Capitol Hill community members know that the EcoDistrict intends to help facilitate improvements to the neighborhood in three main ways: social equity, ecological resiliency and cultural vibrancy. While these terms are brimming with buzzwords that now seem to be plastered across any new development's promotional posters, non-profit organization's pamphlets, or a city's action plan, at the time that the Capitol Hill EcoDistrict was created in 2012, these terms were just beginning to take root and gain momentum as important issues for society to focus on. Capitol Hill EcoDistrict 
continues to play a huge role in paving the way for other cities and neighborhoods to take steps towards more sustainable living models. This acknowledgement ties back into the second mission statement mentioned above, which projects that the Capitol Hill EcoDistrict is a national example for other organizations to look to as they develop district-scale action plans to improve their own ecological and community health. Although the term 'national' is used, I argue that they are really speaking to a global audience as the decisions and efforts taken in Capitol Hill around S.U.D. are being watched on an international stage. The main mission statement for The Village also refers to itself as a model sustainable development. Thus, both case studies set out with a similar ambition to become models for the field of S.U.D. to look to. At face value, these intentions are marketed as pure-hearted desires to see communities embrace sustainability at the neighborhood level, but as Vancouver stated in their 'greenest city' action plan, positive ecodistrict publicity also draws financial support from stakeholders and can be a catalyst for future developments.

\section{Specific Objectives and Project Goals Refer to Appendix A}

Along with each ecodistrict's primary mission statement, there are multiple sub-statements that provide deeper insight into the specific performance goals and metrics that the ecodistrict teams are working to meet. These objectives pertain to more specific subjects like installing more stormwater management features, designing pedestrian friendly streetscapes, or including more energy efficient building strategies and district-scale infrastructure. In the case of The Village, one of the most unique city-written design objectives was titled Social Benefits and called for "increased community connection to the environment, more park and community spaces, and increased community capital" (City of Vancouver, 
1999). While this objective did result in the construction of a large green space called Hinge Park, multiple community gardens, a dog park, the restoration of Habitat Island, and the construction of the Creekside Community Recreation Center, signs of actual community development and social cohesion are few and far between.

Since the Capitol Hill EcoDistrict formed as an entity separate from the City of Seattle, the non-profit team wrote their own performance goals and objectives. Their EcoDistrict initiatives focus on eight categories of improvement: Culture, Health, Equity, Transportation, Habitat, Energy, Materials and Water (Capitol Hill EcoDistrict, 2012). The main verbs used to describe these objectives are: foster, support, promote, ensure, maximize, enrich, reduce and conserve. Again, these verbs have positive connotations and actions associated with them. Furthermore, each of these eight categories has specific performance targets embedded within. These performance targets again include similar discourse language. While these goals directly apply to the Capitol Hill neighborhood, they also closely resemble the objectives listed in the broader framework created by the EcoDistricts organization in Portland. This framework is called the EcoDistricts Protocol and is a free open-source document that anyone can draw from and apply in their neighborhood. This Protocol helps EcoDistricts evaluate a district's action plan before officially certifying it as an EcoDistrict. Appendix B compiles key dates related to the formation of each ecodistrict, enactment of city policies and the development of the EcoDistricts organization. Looking at the timeline, the EcoDistricts Protocol wasn't officially completed and published online until 2013, which is after Capitol Hill EcoDistrict was created in 2012. While the Lloyd EcoDistrict in Portland was EcoDistricts' first pilot project, Capitol Hill EcoDistrict also played a role in shaping its parent organization. Conversely, the Protocol 
helped the Capitol Hill team develop its specific goals. The interconnection and relationship between the evolution of these two entities speaks to the defining and formalizing of the larger discourse community vocabulary of the emerging field of sustainable neighborhood development. This niche within the urban design discipline really began gaining momentum at the turn of the century when Sweden began developing ecodistricts. Now, some of this discourse terminology has become everyday language in city action plans, architecture firm profiles and non-profit publications. This is a huge victory for society and the planet as new audiences are becoming aware of the importance of urban sustainability and more communities are engaged in sustainable development projects.

\section{Discourse Analysis - Graphic Language}

Another primary form of discourse within the fields of architecture and urban design is graphic language. Graphics are a very effective publicity tool because a single rendering image can convey a multitude of visions and goals for a project. The publicity renderings differ greatly between The Village and Capitol Hill EcoDistrict, partly because the two projects had very different initial base site conditions and partly because the project teams had different development strategies and goals. First, The Village started at ground zero with a vast, empty brownfield while Capitol Hill EcoDistrict was launched in the heart of Seattle's densest urban neighborhood, which was already heavily developed and filled with physical and social infrastructures, some of which were created over a century ago. Thus, The Village design team had to create an entirely new built environment, and it appears that step one for them was to visualize the buildings themselves rather than the ways people would interact with and occupy the spaces. As a result, The Village's graphics are much more building-centric, with flashy 
architecture renderings depicting the entire development from a bird's eye view. There are very few ground level renderings, which typically focus on street life and streetscape envisioning. On the other hand, Capitol Hill EcoDistrict's design team had an entire pre-existing built environment to work within. The team's intentions were not to create an entirely new environment, but rather to retrofit the existing one by placing more sustainability-related features into it. Thus, their renderings are primarily personality collages that focus more on depicting individual sustainability features and the experience of the built environment by people rather than depicting the aesthetic of buildings. These images are filled with vibrant colors and depict a multitude of social activities occurring within the neighborhood and its streets.

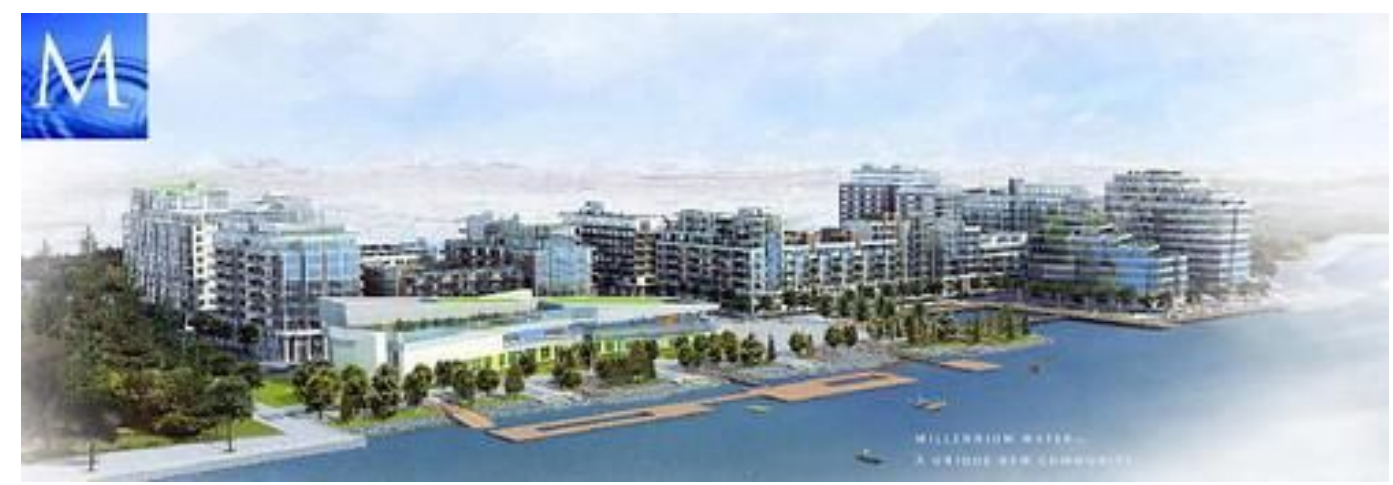

Image: The Village on False Creek Promotional Rendering Source: Millennium Development Corporation

The Village's graphic promotional narrative parallels Capitol Hill EcoDistrict's concerning ecological sustainability features included in the design schemes, but differs greatly in terms of emphasis on social infrastructure and community development. Above, this bird's eye view rendering highlights the LEED Platinum Creekside Community Recreation Center and the waterfront boardwalks, but offers no insight into the user experience of the space. The collage below is one of the few street view renderings of The Village neighborhood, and was 
created by an artist to represent his sparrow sculptures commissioned as part of the Olympics displays. Even this rendering shows barely any context and the characters seem to be aimlessly passing through the plaza with no prescribed activity. It is understandable that the sculpture artist would highlight his bird sculptures rather than spend a lot of time enhancing the backdrop and peripheral activities, but, ironically, the mood of this collage is actually very similar to how the public plaza really felt when I visited it in March. A sense of placelessness carried with me throughout my entire site visit. Yes, there were flashy buildings and beautiful luxury condos to drool over, but the streetlife was severely lacking. I barely saw any other pedestrians in the neighborhood other than at the park. The lack of street level renderings points towards the lack of attention given to the public realm and streetscapes within The Village. While pristinely built and maintained, the public spaces were very unactivated, and many of the buildings had ground level apartment units with private entrances rather than ground floor retail or commercial spaces.

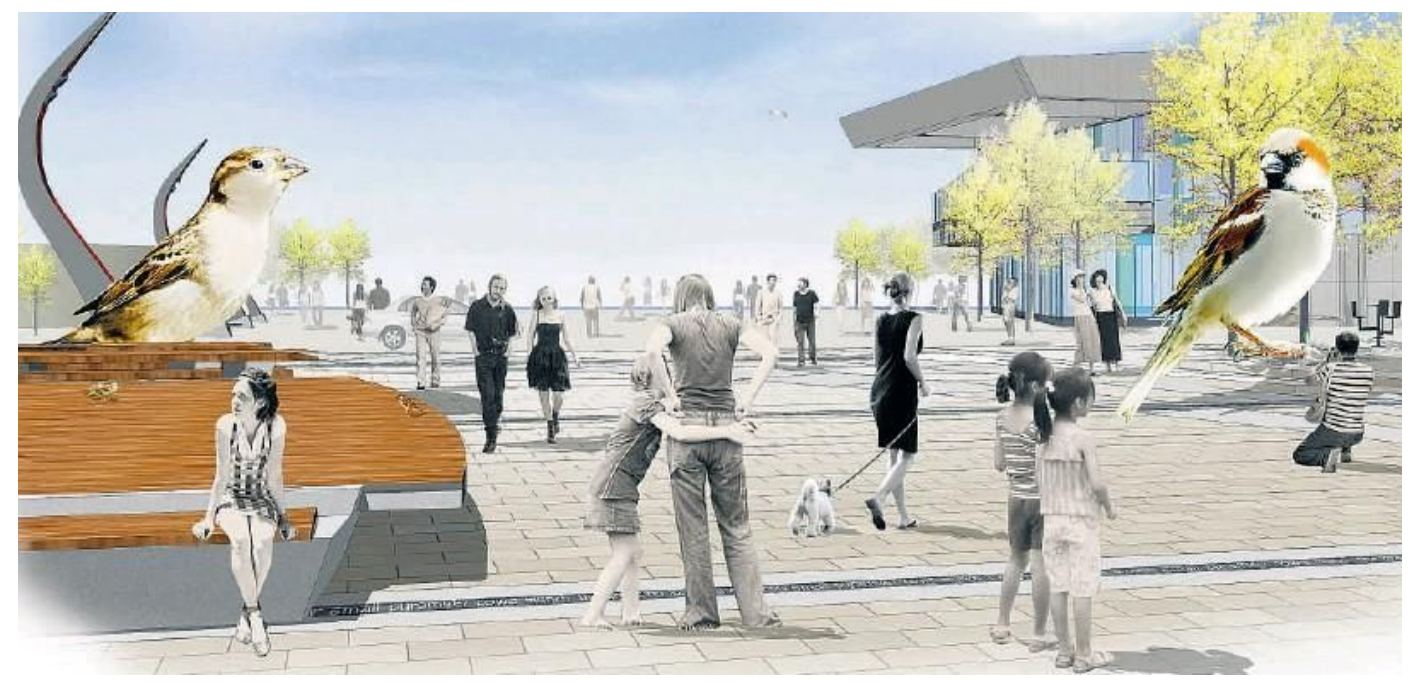

Image: Collage Rendering of Vancouver Olympic Square Source: Kevin Griffin 
Capitol Hill EcoDistrict's renderings are much more engaging and lively, as is the actual neighborhood. The following renderings were created in 2015 by designers at GGLO, based in Seattle, as part of the envisioning phase of the Capitol Hill EcoDistrict. The Capitol Hill Community Blog even refers to these images as 'early promotional graphics' for the EcoDistrict (JSeattle, 2015). The three collages demonstrate how key ecological sustainability features, public transportation routes, social infrastructures, walkable neighborhood concepts, and mixed-use spaces can be incorporated throughout the EcoDistrict. They represent the EcoDistrict team's values and goals for the neighborhood, and reflect desires to stimulate more community engagement and promote healthy interactions between residents, business owners, and visitors. Vibrant colors, high levels of pedestrian and cycling activity, dense natural vegetation, and flashy buildings are layered throughout the series of images. Most of the sustainability features present in the renderings target more than just one of the goals laid out in the EcoDistrict's mission statement. For example, bioswales are creatively used for multiple purposes: they address stormwater management on the Hill, serve as a buffer zone between foot traffic and vehicle traffic, and they also create habitat corridors for wildlife.

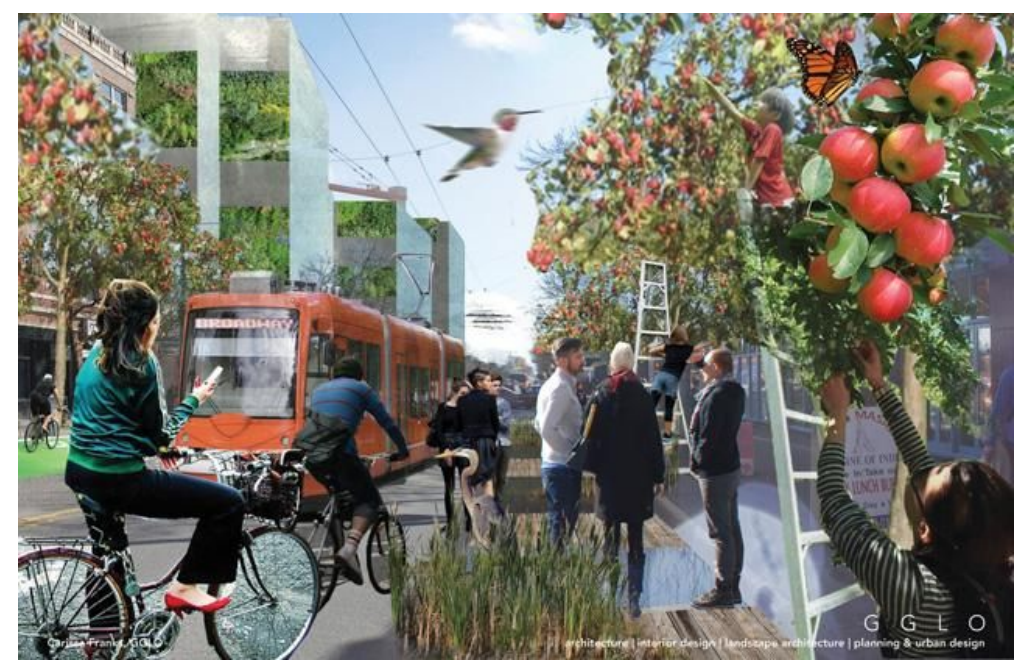

Image: Capitol Hill Envisioning Rendering 1

Source: Carissa Franks, GGLO Design 
In the envisioning collage above, there are many layers of information to examine. In the foreground, three children reach for apples from an urban orchard, presumably public, planted alongside the street. Apple trees line both sides of the street and disappear into the background. This idea of urban farming is gaining momentum for many reasons. Many children who grow up in urban environments rarely have the opportunity to interact with their food sources. Urban farming is also beneficial as habitat for native species such as insects and birds. Also in the image, a butterfly perches on an apple and a hummingbird zooms through the sky. One of the key focuses in this collage is to depict the layers of separation between vehicles and pedestrians. A boardwalk and bioswale are the main barriers, providing stormwater management as well as habitat for a blue heron. A group of people who look to be nearby office workers stand and chat while a group of urbanite millenials hang out in the background of the boardwalk. The street itself is dominated by three cyclists and a streetcar. The telltale lime green-painted bike line streaks through the background. The buildings have plant green walls installed on them, which serve as a shading barrier, habitat space and biophilic form.

All of the elements present in this collage align with Capitol Hill EcoDistrict's mission statement and written goals. Specifically, one of the EcoDistrict's listed strategies to improve social equity in the Capitol Hill community is to: Develop a Community Fruit Tree Harvesting \& Food Bank Donation Program (GGLO, 2012, p. ix). Another strategy is to: Grow a Capitol Hill Community Orchard to reach the community health target. Demographically, the neighborhood currently has a very low number of families with children, so the high ratio of children to adults in this image speaks to a desire to see more age diversity and families move into the area. 


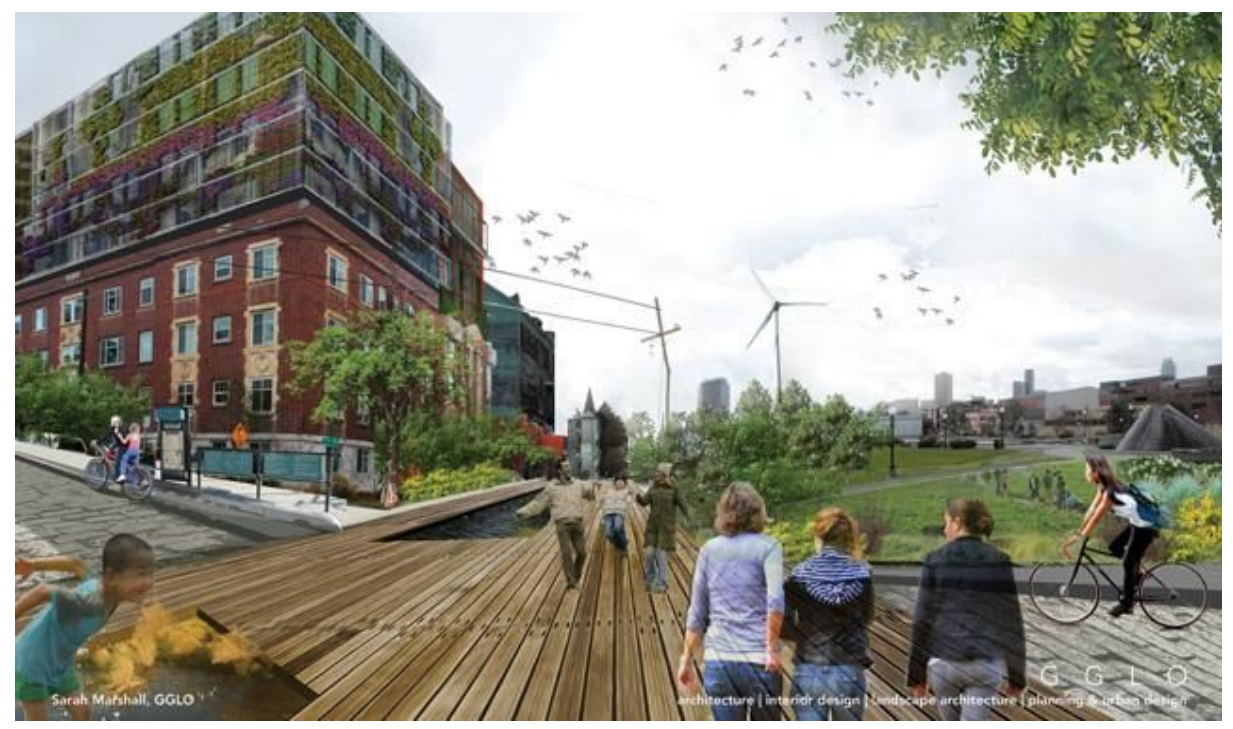

Image: Capitol Hill Envisioning Rendering 2

Source: Sarah Marshall, GGLO Design

While this second collage depicts many of the same ecological and social elements that were present in the previous collage, there is more visual breathing space here, which allows the eye to focus on the physical qualities of the built environment. First, the mid-rise historic brick building has been renovated with what GGLO calls an eco-tapestry. To the right, Cal Anderson Park, the neighborhood's iconic central green space, hosts a large wind turbine and a flock of birds fly straight towards its perilous propellers. Nevertheless, the streetscape itself is very environmentally friendly, as its pavers leave room for water to infiltrate between and into the ground. These pavers are a good stormwater management strategy, but are sometimes criticized for creating an unsafe surface for people with mobility limitations to move safely across. Bioswales line the wooden boardwalk as parents swing their giddy child in the air. Again, thirty percent of the people in this image are children. While the Capitol Hill neighborhood has the steepest topography in all of Seattle, a mother nevertheless pedals up the steep hill with a child in tow. She bikes past neighborhood wayfinding signs and a public bus stop. 
Many of the elements in this second collage again speak to specific EcoDistrict goals listed in the Proposal report. A few of the most relevant ones are: Prioritize Active Transportation, Improve Wayfinding around District and to Various Transportation Options, Enable Car-Free Households, Advocate for Pedestrian Infrastructure and Funding, and lastly, Prioritize High-quality, Habitat-creating, Flexible Open Spaces such as parks, plazas, community gardens and recreation fields (GGLO, 2012, p. x). Cal Anderson Park is a key flexible open space in the neighborhood, even hosting the annual Capitol Hill Community Garage Sale every August (Cal Anderson Park Alliance, n.d.). As active transportation is a key highlight in this rendering, there are no vehicles depicted.
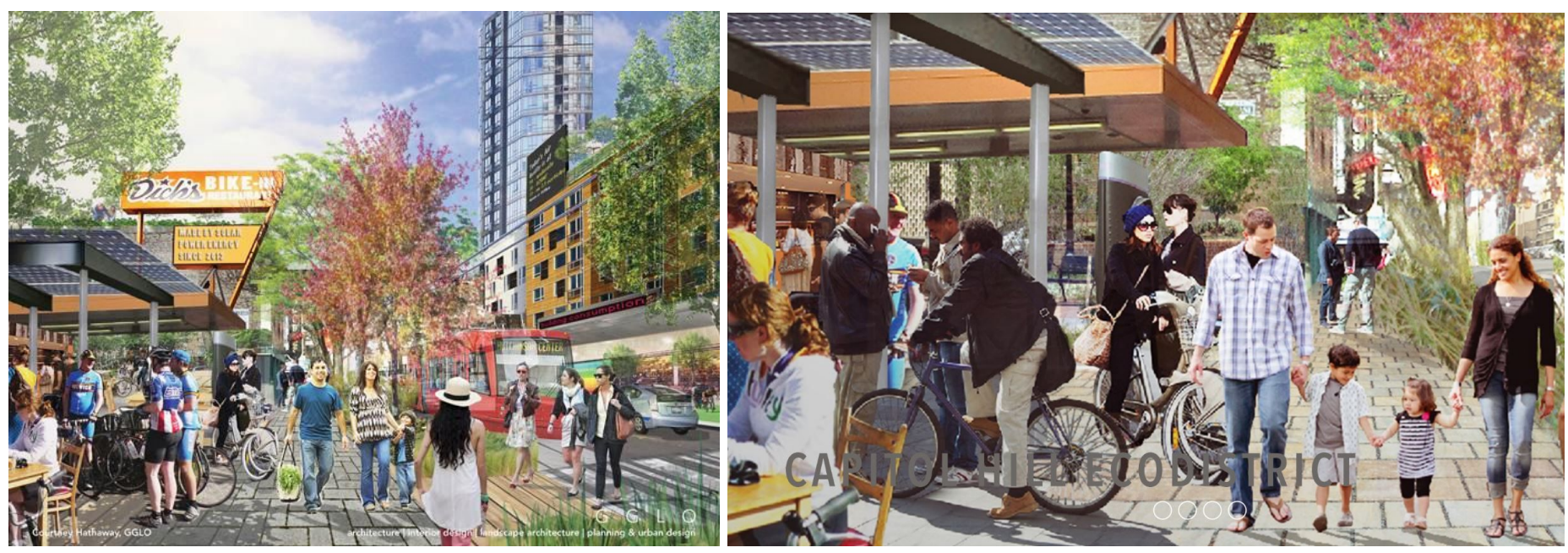

Images: Capitol Hill Envisioning Rendering 3 - Iteration 1 and Iteration 2 Source: Courtney Hathaway, GGLO Design

This third image, created by another designer at GGLO, is the most widely circulated rendering of Capitol Hill EcoDistrict. It is the background on GGLO's website profile for the EcoDistrict project. The primary focus of this collage is the activation on the street itself. Pedestrians, cyclists, electric cars, and public streetcars coexist harmoniously in this moment, with pristine landscaping providing a divider between the road and the sidewalk. The sidewalk 
is once again surfaced with permeable pavers lined with bioswales and planters. There is also a strong theme of renewable energy mechanisms throughout, specifically related to transportation modes. An electric Toyota Prius is the only car driving past on the street next to the electric streetcar. A group have dedicated cyclists have stopped to refuel at Dick's Bike-In, which is actually called Dick's Drive-In. The pavilion roof on the Bike-In is made of solar panels. A sign on the gold building to the right displays statistics about the energy use of the building in order to educate the public and raise awareness about energy conservation and innovative technologies. This sign speaks to the strategy: Visualize Energy Use - Dashboards \& Pavement. While most of the elements in these collages are just hypothetical representations of the design team's values and visions for the Capitol Hill EcoDistrict, some of the icons used are a bit kitschy, especially when it comes to addressing environmental sustainability. Renewable energy tropes like solar panels, Priuses, and wind turbines are an easy way to wave the sustainability flag to the rest of the world. The icing on the cake is the literal greenwashing of buildings by pasting plants onto their facades and calling them eco-tapestries. As Capitol Hill does have a thriving art community, it would have been a nice addition to see more art depicted in the renderings, such as murals or community event posters.

In terms of the people represented in these collages, there is a glaring lack of demographic diversity. Elderly folks, ethnic minorities, lower socioeconomic classes, and people with mobility limitations are few and far between, often entirely nonexistent. Everyone appears to be relatively affluent, clean-cut, slim and trim, and mostly fit the profile of the typical 'young urban professional.' While this does accurately portray the current existing demographics in the neighborhood, as envisioning collages, these renderings are meant to 
portray dreams for the future, not the current reality. The first iteration of the third rendering had the most homogeneous demographic portrayal of the three images. The second iteration, which is the one posted on GGLO's website, replaced the white family walking down the central sidewalk with a biracial family. The group of white, male, affluent-looking cyclists stopped at Dick's Bike-In were also switched out for a group of African-American men with bikes. This group of men looks to be from a lower socioeconomic class than the group of men in the first iteration, which is an interesting insight into the interconnectedness between race and our perceptions about socioeconomic class structure. It is also interesting to observe how those stereotypes are perpetuated through graphic representation in the traditionally white, male-dominated architecture field. While the EcoDistrict's written mission statements promise to promote diversity and support minority communities, the fact that these three images initially all missed that mark yet were created by three different artists raises a slight concern in terms of who this urban 'ecotopia' is truly intended for. This serves as a reminder of the importance of considering representation during all phases of a project, especially during the initial envisioning phase of a project.

In conclusion, the graphic publicity language is, for the most part, consistent with the written rhetoric for Capitol Hill EcoDistrict (GGLO, 2012), but there are key differences between The Village's written design intent and its neighborhood renderings. While much of The Village's written branding centered around environmental sustainability, livability, and affordability, the graphics depict a more accurate version of what the neighborhood actually turned out to be. The graphics are very reflective of the development team's priorities, which were to mass produce luxury condominiums that could be sold at a premium price to 
international clients, rather than create a generative urban ecology that could actually sustain a vibrant and heterogeneous community. The Village's aerial renderings mimic so many generic renderings of luxury high rises painted with lush greenery that are being produced globally in the current fad of 'green' design. This international trend most certainly played a role in elevating The Village onto the global stage of S.U.D.

\section{Part Two: Process of Development Refer to Appendix $B$}

Along with publicity material, examining the processes of development for ecodistricts reveals many of the true intentions and values held by the development team towards their projects, exposing moments where a decision was made to cast aside an objective or to change course slightly in order to ensure that a project element of high value to both the team and the neighborhood got followed through to the end. There are many processes that can be tracked throughout the development of an ecodistrict, from formation to city facilitation to implementation to the creating the framework to guide future project phases. Development processes are also inherently dependent upon the type of development. The Village was a 'blank slate' development, whereas the Capitol Hill EcoDistrict team had and still has to take an incremental urban infill approach. Another key factor that affects development processes is the partnerships that are made to facilitate projects. These can be between the public and private sectors, ie city planners and architects, policy makers and developers, or community nonprofits and local business owners.

One of the most successful aspects of the EcoDistrict development framework is that it places a considerable emphasis on the formation phase of projects. The EcoDistricts team in Portland believe that spending more time on the front end drafting decision-making guidelines, 
ecodistrict intentions and values, collecting community feedback, and selecting members to be on steering committees results in better project outcomes later on. Drafting extensive performance metrics and project objectives in the formation phase ensures that once projects are implemented, the results can be evaluated via those metrics, and specific improvements can be made if need be. While the EcoDistricts model sets projects up for long term success, the LEED certification process focuses mostly on the design and construction of buildings rather than how people actually interact with the spaces, only requiring a post-occupancy performance analysis after the first year of occupancy. While Millenium Development Corp hired six architecture firms, numerous consultants, partnered with multiple other real estate investment firms and worked with the City to use their planning guidelines to plan the physical layout of The Village, the team did not spend nearly enough time planning the social human aspects of the project. As a result, there were a lot of shortcomings once the project actually went into the implementation phase and later full occupancy. This experience deeply influenced Rob Bennett and Tom Osdoba, who both worked on The Village, causing them to create the EcoDistricts organization based in Portland (EcoDistricts, 2018).

Capitol Hill EcoDistrict spent much more time on the front end than The Village did on developing their values and mission statements, resulting in a much more viable framework for their projects. The team was able to move at a slower pace because they didn't have an Olympics Opening Ceremony deadline looming overhead. In the Capitol Hill EcoDistrict Proposal Report, drafted by Capitol Hill Housing in partnership with GGLO Design, the team wrote that their first EcoDistrict formation steps would be to: "Engage stakeholders, create a steering committee, develop vision and priority commitment documents, determine 
stakeholders' roles and responsibilities, formalize the EcoDistrict governance entity" (GGLO, 2012, p.9). This report also outlined six phases of the approach that the team would be taking to create a functioning EcoDistrict: "Research on site context and ecodistrict best practices, Outreach, Defining the overall EcoDistrict's vision, Establishment Strategies and Metrics, Implementation and Performance Measurement" (GGLO, 2012, p. 116 Appendix D). The Capitol Hill team lists seven specific criteria that they use to guide their decision making: "projects must be place specific, scale appropriate, measurable, relevant to real issues, congruent with partner organizations, evaluated and adjusted over time, and easy to communicate." All of these criteria demonstrate the steering committee's commitment to address social equity and engage the community during the design process, as well as their desire to pursue place and scale-appropriate projects that are sensitive to the surrounding context.

The EcoDistrict model is also successful because it emphasizes the importance of having a solid team in place to facilitate the ecodistrict programs. Partnerships between key entities, whether public or private, are crucial in large-scale projects like ecodistricts. City governance and project oversight play a large role in facilitating ecodistrict initiatives. Both Vancouver and Seattle's City municipalities have been heavily involved in The Village and Capitol Hill EcoDistrict from the beginning. In January 2015, Seattle City Council PLUS(Planning, Land Use and Sustainability Committee) formally approved Resolution 35612, which brings formal recognition of the Capitol Hill EcoDistrict from the City, and encourages City Departments to help facilitate the EcoDistrict's success (Sisolak, 2015). The City of Seattle's Department of Planning and Development was heavily influenced by their experiences of working with the 
EcoDistrict, and some of their new policies reflect ideas and language used in Capitol Hill EcoDistrict's Protocol. In 2015, Seattle released its Comprehensive Plan that includes an Urban Village Strategy that directs growth towards urban core areas. This Plan is based on four core values: Community, Environmental Stewardship, Economic Opportunity and Security, and Social Equity. The Plan defines social equity as the sharing of limited resources and opportunities and "the inclusion of under-represented communities in decision-making processes" (City of Seattle DPCD, 2016).

One key player unique to Capitol Hill's EcoDistrict is Capitol Hill Housing, which is a community development corporation and Seattle's public development authority. $\mathrm{CHH}$ has served the Capitol Hill neighborhood for over forty years, working to "enhance community health and affordability" (Capitol Hill EcoDistrict, 2012). Chris Persons, CHH's CEO, initially proposed the idea of an EcoDistrict (Capitol Hill Housing, 2009), and CHH was the primary supporter throughout the entire EcoDistrict formation process and continues to support development initiatives within the EcoDistrict. The Village in Vancouver unfortunately did not have an entity like $\mathrm{CHH}$ involved throughout the entire project, but there should have been an affordable housing advocacy group put in place due to the ambitious initial plan to keep 250 units of the total 1,108 for affordable housing. As Capitol Hill EcoDistrict was spearheaded by the public sector, The Village's actual design team comprised mostly of private sector entities, which could explain the massive fallout of the affordable housing initiatives. Millennium Development Corporation was The Village's primary developer. They hired six architecture firms, led by Merrick Architecture, to design the fourteen blocks of the neighborhood. The primary private sector actor in Capitol Hill EcoDistrict is GGLO Design, which is a 
Seattle-based architecture, interior design, landscape architecture, planning and urban design multidisciplinary firm. GGLO has also remained committed to the EcoDistrict since they helped write the initial feasibility report and create the early envisioning collages.

Lastly, community partners are also a valuable asset to an ecodistrict team, and should be engaged as soon as possible to ensure that the ecodistrict objectives actually focus on improving the neighborhood in ways that the communities, whether residential or business owners, actually desire. The field of sustainable neighborhood development is finally starting to actually understand that sustainability is no longer just about producing cutting edge buildings that achieve environmental sustainability standards. Cities and design firms are beginning to prioritize engagement of the public and local community in design processes, and to consider their needs when creating a new development. While Capitol Hill EcoDistrict is working to engage people of many socioeconomic classes living within the neighborhood by reaching out to homeowners and renters, there is no indication that The Village even appointed a community development team.

Another factor that greatly affects development processes is the pace of development. The Village and Capitol Hill EcoDistrict had extremely different paces of progression, which largely contributed to the shortcomings of The Village and the continued successes on Capitol Hill. Once Vancouver won the 2010 Winter Olympics bid, the City had to come up with a location and development plan to build enough units to house hundreds of athletes and officials, all of which had to be completed in time for the Games to begin. This high pressure deadline resulted in some design ideas that were not fully thought through. Furthermore, the team ambitiously included numerous cutting edge green infrastructure technologies, some of which 
do not function as well as intended. Budget went through the roof, bankruptcies occured, and residents began sueing the development for false promises of luxury sustainable living on False Creek. Residents also complained about not being educated on how to properly use the energy-saving heating system, which consequently resulted in system inefficiencies and misuse. The rainwater used to flush the toilets was also not filtered enough, causing unpleasant smells and discoloration. Some experts have speculated that this gap between design and performance is due to possible errors during construction, the absence of support from operations and maintenance staff, user misuse, and accuracy of models utilized to predict use (Bordass et al., 2004). Following its rapid design, rapid construction, and rapid sale of units, The Village has since fallen out of the sustainable development limelight. There are few signs of positive community development occurring, and the neighborhood felt stagnant and lifeless when I visited.

On the other hand, the Capitol Hill EcoDistrict is still very much in its hay day, moving forward with projects, community initiatives, design guidelines, and website blog posts daily. While it doesn't always appear that that much has changed within the Capitol Hill EcoDistrict since it was founded, the aspects that have changed have been very well thought through, and the community has engaged and participated greatly throughout so that these projects are seen as very successful in the eyes of everyone, not just in the pockets of a few developers like as was the case in the Village. Capitol Hill's success here, I argue, is largely due to the pace at which the team is moving forward with projects. Albeit, part of this is not by choice, as the urban fabric is already densely occupied and developed, so there isn't as much opportunity for large scale physical development projects. Rather, the steering committee and Capitol Hill Housing are challenged to work creatively and innovatively to carry out their smaller projects using an urban infill approach. in wherever. After noticing the benefits of this slower 
incremental change approach, the EcoDistrict team has started to intentionally embrace this development method, with the steering committee focusing on one or two projects at a time from start to finish before moving on to new projects.

There are many benefits to this incremental approach. First, the ecodistrict team has the opportunity to learn from their past projects and identify areas for improvement, especially in the facilitation process, going forward. In the case of The Village, the design team did not leave much room for future infill projects, instead developing almost every square inch of land in the area all at once. This is a risky approach, because it is highly unlikely that any team will have included every ideal element in their design scheme, and by choosing not to leave available spaces for the communities that move into the new neighborhood to help design and develop it in the future, the community is robbed of the potential to experience greater sense of ownership. Even though there is now a large residential community living in The Village, there is very little evidence of a community identity being formed, and there is no community development group appointed to help facilitate this process. Perhaps in twenty years a community ideology will emerge, but as of now, The Village felt very disconnected, passive and idle when I visited. Capitol Hill EcoDistrict set both short term implementation and long term implementation targets for itself, which The Village team should have set. Below is GGLO's timeline of EcoDistrict projects as they relate to larger City of Seattle targets:

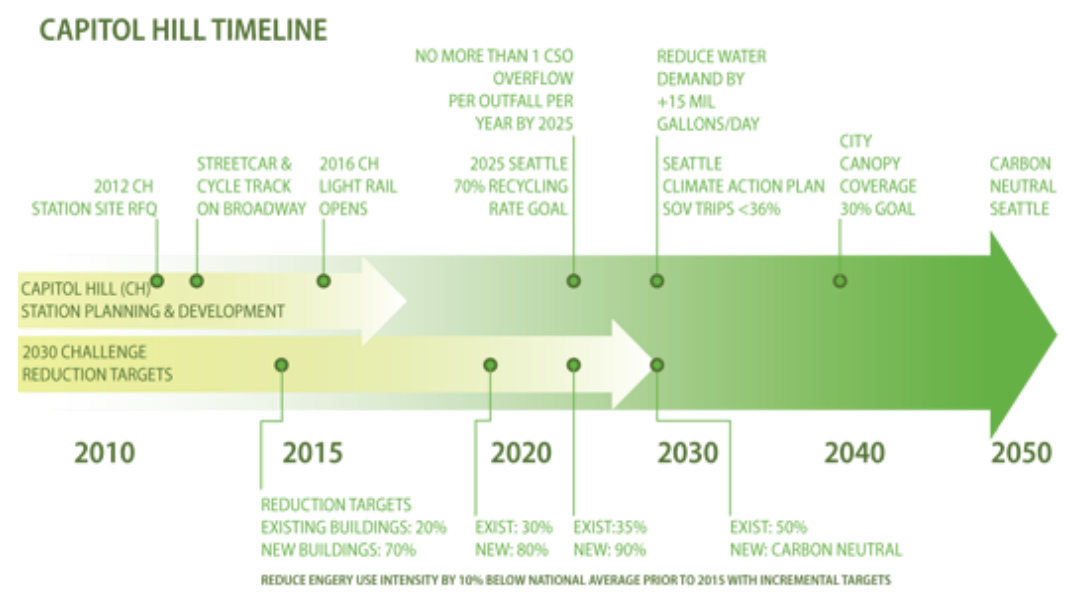

Source: GGLO Design 
Earlier in Capitol Hill EcoDistrict's formation, the design and implementation teams focused on creating an EcoDistrict Index with measurable performance goals, implementing Community Solar and District Shared Parking, promoting a Capitol Hill Arts District, working with community businesses to come up with Green Business solutions, making pedestrian-friendly streets, and addressing dumpsters in the right-of-way (CH EcoDistrict and $\mathrm{CHH}$, n.d.). In 2015, their future plans were to focus more on community engagement, update the Capitol Hill City neighborhood plan, and focus on affordable housing initiatives. The EcoDistrict has since partnered with the City, CHH, King County Metro, Seattle Department of Transportation and HALA: Housing Affordability and Livability Agenda to bring these initiatives to fruition. Currently, the team is focusing on six target performance areas that guide the focus of projects: "Building climate and cultural resilience, engaging renters as neighborhood and city leaders, enabling right-size parking and increased mobility, improving the health and safety of public spaces, informing new development in the neighborhood with their EcoDistrict Priorities, and promoting resource conservation" (Capitol Hill EcoDistrict, 2012). Some of these goals are long-term and more comprehensive, while others are slated to be addressed immediately and might be smaller scale endeavors.

\section{Part Three: Public Space as Social Infrastructure}

Looking at the social dynamics within both ecodistricts, The Village and Capitol Hill EcoDistrict have played large roles in the creation of social capital in their neighborhoods. Because the land for The Village was previously vacant, this development created an entirely new community of residents, businesses and tourists in 2010. Thus, many components of The Village's design scheme can be seen as social infrastructures, and therefore evaluated for the 
roles they play as social facilitators and social capital generators. It is also important to consider social infrastructures that are absent from the neighborhood. While The Village incorporates physical social infrastructure into the scheme, social organizations are not evident in the neighborhood, despite the fact that there is ample space for groups to gather and connect. Conversely, Capitol Hill EcoDistrict has sought to play a positive community development role in its neighborhood, bringing together many different groups of people who are all connected to Capitol Hill in some capacity and thus invested in its wellbeing. The Capitol Hill EcoDistrict team has done a very good job of serving its local communities, as well as providing room for the communities to participate in the design process. As part of the initial EcoDistrict feasibility report (GGLO, 2012, p. 22), Capitol Hill Housing and GGLO Design created a Community Assets Map (See Appendix C) which highlights amenities, key social infrastructures, and areas lacking certain beneficial elements. Along with making sustainable improvements to the built environment, Capitol Hill EcoDistrict also focuses on fostering sustainable behavior change by increasing access to information, education, and incentive programs (GGLO, 2012).

One of the key pillars of any ecodistrict project involves creating, preserving, or enhancing natural green spaces and open spaces within neighborhoods. Especially within dense urban areas, central public parks and plazas provide essential breathing space that contributes to a healthy living environment for residents, workers and visitors alike. The Village's Hinge Park is not only a beautifully designed green space, but it also acts as social infrastructure for numerous groups of people, which I was fortunate enough to observe when I visited the site in late March of 2019. At the time, two mothers were playing baseball with their primary school ages sons while daycare chaperones supervised as their class of toddlers played on the 
industrial-themed play structure. People of all ages socialized at the dog park, and an elderly woman tended to her plot in the community garden while two middle-aged men jogged past on their lunch break presumably.

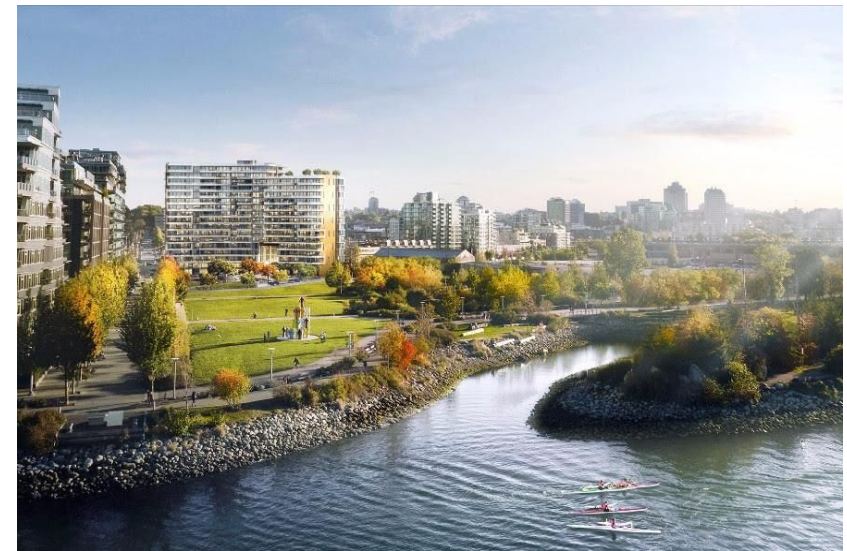

Image: Hinge Park and Habitat Island near The Village Source: Concord Pacific

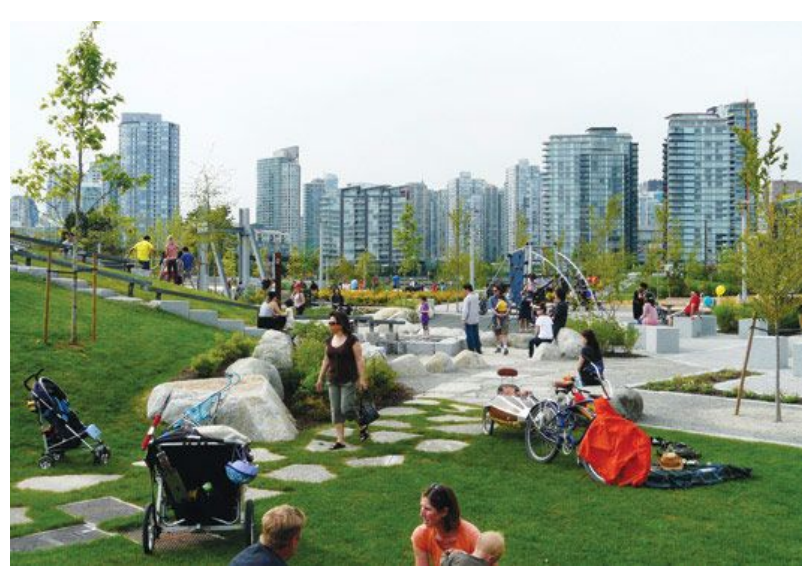

Image: Hinge Park

Source: PWL Partnership Landscape Architects

In Capitol Hill, Volunteer Park, Interlaken Park, and Cal Anderson Park are all utilized by many local communities. Can Andersen is the largest central green space in the neighborhood, and is heavily used by a myriad of different local communities. When I visited, I observed a group of skateboarders hanging out and skating, multiple African-American families barbequing while their children played in the water feature, and groups of young adults studying and picnicking in the grass. The City of Seattle describes Cal Anderson Park as "the heart and soul of the Hill" (Williams and Kendle, 2019). In the photo below, the annual Community Garage Sale takes place. There are also many pocket parks tucked within the urban fabric of the neighborhood, providing spaces for an individual to still enjoy the public realm but in a more intimate and private setting. There are also three small neighborhood gardens in Capitol Hill called P-Patches, that are maintained by local residents. 


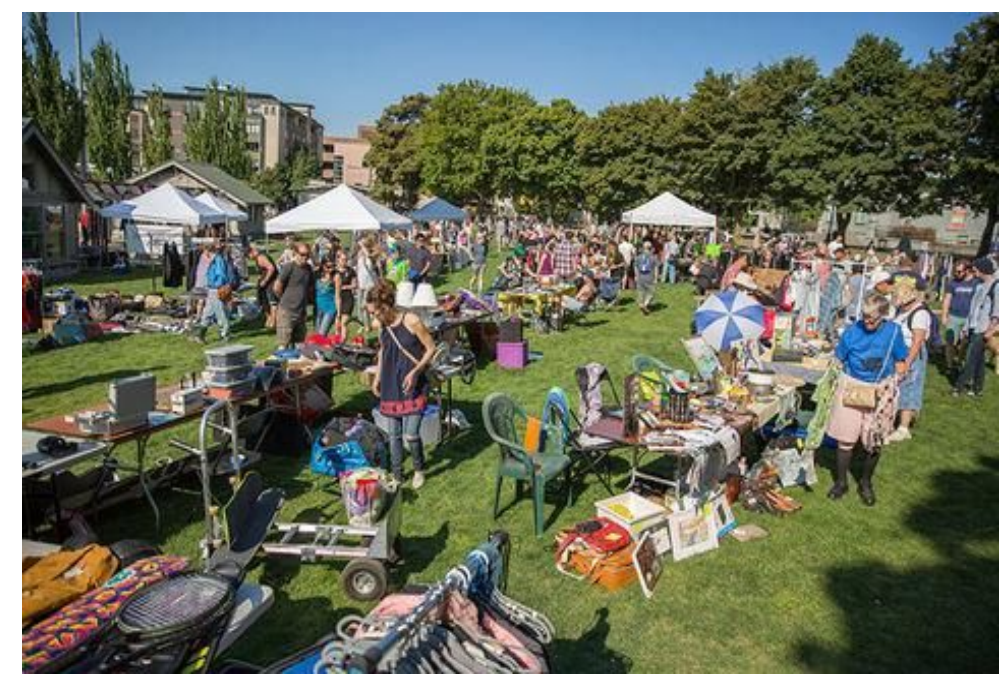

Image: Capitol Hill Annual Community Garage Sale Author: Cal Anderson Park Alliance (CAPA)

Another natural environment feature that serves as social infrastructure is The Village's waterfront. Dragon boats, canoes, small motor boat scenic tours, and kayaks dotted the inlet during my site visit, and children scoured for seashells along the rocky shoreline. Bike paths wind throughout the entire neighborhood, connecting Hinge Park to the Creekside Community Recreation Center, where parents were seen walking out of after their children's swim lessons and young women were seen walking into for spin class. One benefit to a blank slate development like The Village is that the architects were able to add a new community recreation center in a choice site location, whereas Capitol Hill EcoDistrict would most likely need to creatively retrofit an existing building if they wanted to create a recreation center.

A third important social infrastructure element is the public plaza. The Village's primary public plaza is called Olympic Village Square, and was depicted in an earlier rendering collage showing the large sparrow sculptures. Below, the plaza is activated by tourists during the temperate summer months. The scale of this plaza feels disproportionately large now that the Olympics are over. In general, The Village team failed to create viable social infrastructure that 
could still function well post-Olympics. The team was uniquely challenged to create public spaces that could accommodate large groups of people during the Olympics in 2010, but now the scale of those spaces feels far too large compared to the number of residents and tourists actually using those spaces. Even though the residential buildings are at full capacity, the neighborhood feels so empty, which could partially be attributed to the sheer scale of many of the built environment features.

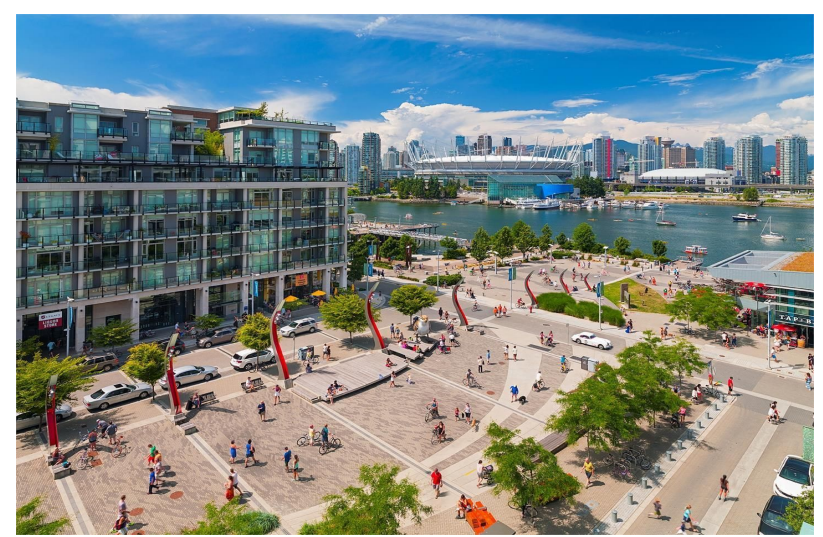

Image: Olympic Village Square, Vancouver Source: Vancouver Magazine

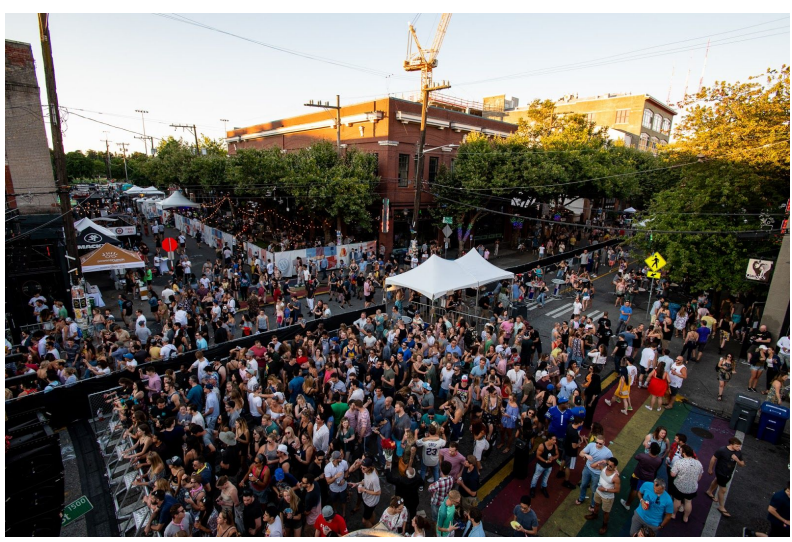

Image: Capitol Hill Block Party, Seattle Source: Capitol Hill Seattle Blog, July 22, 2018

While Capitol Hill EcoDistrict doesn't have the luxury of large swaths of relatively flat, undeveloped land that they can turn into public plazas, the community instead closes its streets to vehicles on certain occasions to make space for public events. One example of this is the annual weekend-long music festival called Capitol Hill Block Party that happens every July. These temporary closures provide a unique dimension to Capitol Hill's public sphere. 


\section{Part Four: Global Visionary but Locally Exclusionary}

The Village on False Creek plays multiple roles in its local community as well as on the global stage of architectural spectacles. While The Village did achieve the global recognition it sought through its environmental sustainability features, it did not come close to achieving the local social equity goals that were listed in the project's initial mission statement. Despite the language in the Core Project Principles around promoting cultural vitality, creating a complete community, enhancing the social environment and livability, and consulting the community to maintain accountability, there are virtually no signs of any of these principles being actively pursued. The project also falls short in addressing social equity and the needs of the lower income community that was promised a large share of units in the development. As is common with large development housing projects, the affordable housing subsidies were cut as soon as the financial viability of the project wavered in the slightest. Originally, 350 residential units out of the total 1,108 units were set aside for affordable housing (Eesmyal, n.d.). However, after the bankruptcy fiasco, the number was reduced to 252 units in 2006 , before the project was even constructed. Furthermore, the number was halved again when another 126 units were set aside for public service workers, such as nurses and teachers (Mackin, 2014). In the end, only eleven percent of the total units ended up being affordable housing units (Westerhoff, 2016, p. 49). This string of harsh seeming reductions, some of which took place before all of the bankruptcy scandals, goes to show that the city planners and stakeholders did not actually hold social justice as a high priority in the project, even though it was stated in the fifteen Project Priorities.

This obsession with profit margin, perpetuated by the real estate development actors, has very negative effects on disadvantaged populations. Millennium Development did not properly 
manage the finances of the project, and when they went bankrupt midway through the project, the affordable housing initiatives were the first components to get cut. Typically, Olympic housing villages are converted into affordable social housing projects post-Games. With this end in mind, the complexes are usually constructed with low quality materials and energy wasting systems. The complexes are usually not maintained very well. Vancouver's Olympic Village is different because it was designed with the intention of being converted into luxury condominiums to rent or sell once the Games were over. Thus, the project was built with higher quality materials and included many sustainable design components in order to attract a more affluent clientele. Gregory Borowski, one of the principals at Merrick Architecture, stated that the project was “designed as a legacy use project with condominium-style fittings" (Kher, 2010), so he was not worried about the units selling at a premium price post-Games.

However, despite the units selling at a premium price, Millennium Development went bankrupt in 2011, owing the City $\$ 740$ million (Mackin, 2014). The 2008 global economic crash also negatively affected the finances of the project (Westerhoff, 2016, p. 18). As a result, the complex was rebranded from Millennium Water to The Village on False Creek. The City of Vancouver had to take over the neighborhood financing and sell the remaining condos. At the time of the bankruptcy, 1,062 of the 1,108 units were already sold or rented. Post-bankruptcy, the remaining forty-six condos were appraised at \$1 million each, but were given a 30\% - 50\% price cut, which caused fifty residents who had already purchased units at the much higher price to file a lawsuit asking for refunds because they felt they were not delivered the luxurious, eco-friendly apartments they were promised (Mackin, 2014). 
The Village's most successful achievement is that it set the precedent for Canada and the world for neighborhood-scale S.U.D. The design team was able to incorporate numerous energy-saving and natural landscape-enhancing features into the scheme, which residents and tourists alike are able to enjoy via the public parks and large pedestrian walkways and bike paths sprinkled throughout the neighborhood. The Village is very energy efficient, with seventy-percent of its heating energy coming from renewable sources. Units include low-flow fixtures and the toilets use gray water collected from rain that falls on the ecoroof. The complex also naturally treats its wastewater through a series of bioswales and natural wetlands that were visually incorporated into Hinge Park to celebrate this achievement. Sixty percent of the development's total footprint was preserved for open space. Additionally, ecoroofs cover over half of the total roof area in the village (Eesmyal, n.d.).

As impressive as these features are on the surface, many of the new technologies and products used in projects like The Village do not function as well as intended. Often, the projects' sustainability features are used as branding and marketing tools to cover up or even greenwash the underlying social and environmental issues facing cities. These larger problems exist on the scale of urban systems so it is sometimes an unfair expectation that one single building will radically change the behavior of a community or trajectory of a city's urban design visions. The idea of these projects becoming a landmark or urban monument of the future are one good way for these projects to leave a positive, lasting legacy to the world after they fade out of the architecture press headlines. 


\section{Conclusions}

The outcomes for The Village and Capitol Hill EcoDistrict differ for a variety of reasons, all of which serve as valuable takeaways for future ecodistrict projects, including Portland's Lloyd EcoDistrict. We can evaluate the performance of both ecodistricts against the goals set by each team during the formation phase. In the Core Project Principles, the City of Vancouver envisioned The Village as "a neighbourhood which is integrated with its urban context while protecting and enhancing the social and economic health of its community as well as the health of local and global ecosystems" (City of Vancouver, 2010). The Village on False Creek succeeds at promoting stewardship of ecosystem health, falls short at promoting economic and cultural vitality, did not create a livable neighborhood that protects housing diversity or equity, and has succeeded in its main goal to create a complete walkable, transit-oriented, live-work community. The Village effectively engages with its global audience of planners, designers and real estate developers, but does not interact positively with its local community, largely due to its financial issues.

Capitol Hill EcoDistrict's primary mission statement is to be "A community-driven effort that promotes a socially equitable, environmentally resilient and culturally vibrant neighborhood" (Capitol Hill EcoDistrict, 2012). Since its formation in 2012, the EcoDistrict has championed community engagement initiatives and brought an impressive group of stakeholders together to work on improving their neighborhood's social and ecological sustainability. As Capitol Hill EcoDistrict pursues growth via incremental urban infill, some of the positive results of initiatives enacted today may take years to be fully realized. The EcoDistricts model is meant to help neighborhood stakeholders create frameworks and organizational structures to empower the local community as they work to improve their neighborhood's social, economic and ecological health. 


\section{Recommendations for Lloyd EcoDistrict}

Through my research, I concluded that a slower strategy of infill development and incremental neighborhood change is recommended for communities looking to improve their ecological and social health at a sustainable pace. A slower pace allows for lessons to be learned along the way and then immediately applied during the next phase of development. This strategy also provides more opportunities for community feedback and engagement in the design process. With pauses between phases of development, the EcoDistrict design team is also able to observe how occupants interact with the new neighborhood design features, and make changes accordingly before implementing the next phase. Similar to The Village, Lloyd EcoDistrict doesn't have the advantage of a large, pre-existing community like Capitol Hill EcoDistrict has, who is able to provide suggestions for amenities to be added to the urban context. However, now that Lloyd EcoDistrict's Hassalo on 8th development is fully occupied by residents, and new apartment complexes are being constructed nearby, a burgeoning residential community is prime for engagement in the design process for Lloyd EcoDistrict phase two. Although Hassalo on 8th caters to a few specific demographic groups, this does not mean that future developments in the Lloyd EcoDistrict also need to cater to those same groups.

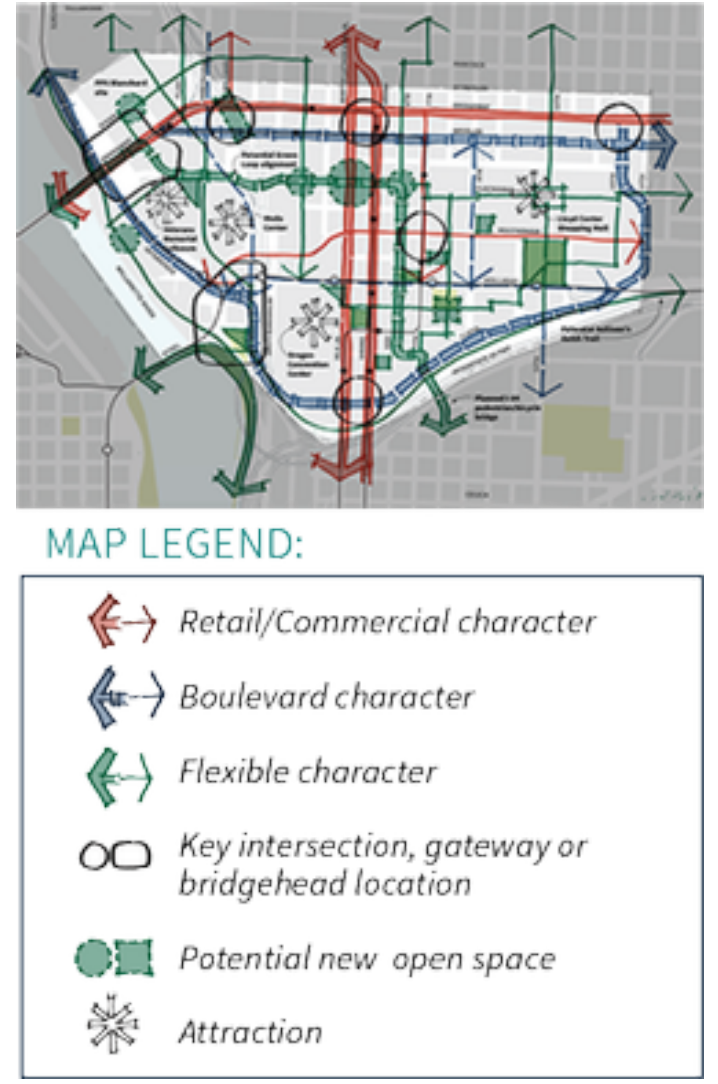

https://www.portlandoregon.gov/bps/article/561903

Above, future connections to Portland's greater context are envisioned within Lloyd EcoDistrict. In this moment, the Lloyd neighborhood has a unique opportunity to stitch a vibrant, lively, colorful and textured cultural fabric together, and by embracing incremental change and engaging community partners, Lloyd EcoDistrict truly does have the potential to become a pillar of social equitable growth and ecological health that other cities and neighborhoods can look to for inspiration and guidance. 


\section{Bibliography}

Assefa, Samuel. Capitol Hill Design Guidelines Update. April 2019. City of Seattle Office of Planning and Community Development (OPCD).

https://www.seattle.gov/opcd/ongoing-initiatives/capitol-hill-design-guidelines-update

Bordass B, Cohen R, Field J. Energy performance of non-domestic buildings: Closing the credibility gap. 2004. Frankfurt, Building Performance Congress.

Boyd, David. "Vancouver 2020 A Bright Green Future: An Action Plan for Becoming the World's Greenest City by 2020." City of Vancouver and Vancouver Economic Development Commission. July 2011. Accessed March 25, 2019. https://vancouver.ca/files/cov/bright-green-future.pdf

Boynton, Emily. Capitol Hill. n.d. Visit Seattle Official Visitors' Guide.

https://www.visitseattle.org/neighborhoods/capitol-hill/

Cal Anderson Park Alliance. Capitol Hill Garage Sale Day. n.d. Accessed April 18, 2019. https://capitolhillgaragesale.org/

Canada Green Building Council. "LEED Impact Report - Canada 2018." Canada Green Building Council. 2018. Accessed May 18, 2019. https://www.cagbc.org/leedimpactreport2018

Capitol Hill Block Party, Seattle. Capitol Hill Seattle Blog. July 22, 2018. Accessed May 2, 2019. http://www.capitolhillseattle.com/2019/02/under-pressure-from-the-city-costs-and-neighbors-capitol-hill -block-party-announces-2019-lineup/capitol-hill-block-party-seattle-wa-july-22-2018/

Capitol Hill EcoDistrict. Advancing Neighborhood Sustainability. 2012. Accessed March 20, 2019. capitolhillecodistrict.org

Capitol Hill EcoDistrict and Capitol Hill Housing. The Capitol Hill EcoDistrict: promoting community health and resiliency. Scribd. N.d. Accessed April 5, 2019.

https://www.scribd.com/document/275089115/Capitol-Hill-EcoDistrict-Presentation\#download\&from_e mbed

Capitol Hill Envisioning Renderings Series. Carissa Franks, Sarah Marshall and Courtney Hathaway. 2012. GGLO Design https://www.gglo.com/perspectives/capitol-hill-ecodistrict/

Capitol Hill Housing. Leadership. 2009. Accessed March 16, 2019.

http://www.capitolhillhousing.org/about/managementteam.php

Capitol Hill Neighborhood Design Guidelines Boundary. City of Seattle. December 1, 2017. Capitol Hill's Design Guidelines to Get an Update. The Urbanist.

https://www.theurbanist.org/2017/12/01/capitol-hills-design-guidelines-get-update/

Capitol Hill Neighborhood Outline. Google Maps. 
City of Portland Bureau of Planning and Sustainability. "Lloyd District 2035 Vision." Accessed May 12, 2019. https://www.portlandoregon.gov/bps/article/561903

City of Seattle Department of Planning and Development. "Comprehensive Plan: Towards a Sustainable Seattle 2015 - 2035.” January 2005. Accessed March 23, 2019.

https:/www.seattle.gov/dpd/cs/groups/pan/@pan/documents/web_informational/dpdd016610.pdf

City of Seattle Department of Planning and Community Development. "Seattle 2035 Comprehensive Plan - Citywide Planning." City of Seattle. Adopted in 2016. Accessed March 23, 2019.

https://www.seattle.gov/Documents/Departments/OPCD/OngoingInitiatives/SeattlesComprehensivePlan/ CouncilAdopted2016_CitywidePlanning.pdf

City of Seattle Office of Planning and Community Development. January 2019 Draft of Capitol Hill Neighborhood Design Guidelines. Posted January 2019. Accessed April 3, 2019.

https:/www.seattle.gov/Documents/Departments/OPCD/OngoingInitiatives/CapitolHillDesignGuideline s/CapitolHill_DG_SEPA_DRAFT_2019_01_17.pdf

City of Vancouver. Clouds of Change. Final Report of the City of Vancouver Task Force on Atmospheric Change. 1990. City of Vancouver Planning Department Library, Vancouver BC. Accessed April 2, 2019.

City of Vancouver. False Creek Flats Area Plan. Approved by City Council on May 17, 2017. Accessed March 18, 2019. https://vancouver.ca/files/cov/false-creek-flats-plan-2017-05-17.pdf

City of Vancouver. "Greenest City Action Plan.” 2011. Accessed March 25, 2019.

https://vancouver.ca/green-vancouver/greenest-city-action-plan.aspx

City of Vancouver. "Host City of the 2010 Olympic and Paralympic Winter Games." Accessed May 14, 2019. https://vancouver.ca/news-calendar/host-city-of-the-2010-winter-games.aspx

City of Vancouver Planning Department. "Southeast False Creek Policy Statement: Toward a Sustainable Urban Neighborhood and a Major Park in Southeast False Creek." Adopted October 1999. Accessed March 12, 2019. https://vancouver.ca/docs/sefc/policy-statement-1999.pdf

Collage Rendering of Vancouver Olympic Square. Kevin Griffin. July 13, 2009. Vancouver Sun newspaper. Accessed April 10, 2019.

Crawford Hampel, Emma. "Canada First in the World for LEED Green Buildings." Business in Vancouver. December 28, 2017. Accessed March 15, 2019. https://biv.com/article/2015/07/canada-first-world-leed-green-buildings.

EcoDistricts. Lloyd EcoDistrict Case Study. October 2017. Accessed May 4, 2019. http://ecodistricts.org/wp-content/uploads/2017/10/ed-case-study-LLOYD-FINAL-oct-2017.pdf

EcoDistricts. “Tracking Our Impact.” 2013-2018 Five Year Report. 2018. Accessed May 11, 2019. https://ecodistricts.org/about/tracking-our-impact/

Eesmyal. "Green Buildings Southeast False Creek: Millennium Water." Eesmyal Blog. Accessed March 21, 2019. http://eesmyal.com/portfolio/southeast-false-creek-millennium-water/. 
GGLO. "Capitol Hill EcoDistrict: A proposal for district-scale sustainability." Capitol Hill Housing. p. ix, x, 1, 4, 9, 22, 116 - Appendix D). March 30, 2012. Accessed March 14, 2019.

JSeattle. EcoDistrict growing into Hill's next big thing. August 19, 2015. Capitol Hill Seattle Blog. Accessed April 12, 2019.

http://www.capitolhillseattle.com/2015/08/ecodistrict-growing-into-capitol-hills-next-big-thing/

Kher, Anuradha. "Vancouver's big win: unlike some other Olympic Villages, the newly named Millennium Water is a permanent installation, on track to becoming Canada's first LEED Platinum neighborhood." Multi-Housing News, July 2010, p. 30. Business Collection, Accessed March 14, 2019. http://link.galegroup.com/apps/doc/A282824455/ITBC?u=s1185784\&sid=ITBC\&xid=360d05b4.

"LEED for Neighborhood Development." Congress for the New Urbanism. Accessed May 10, 2019. https://www.cnu.org/our-projects/leed-neighborhood-development

Lloyd EcoDistrict Map. City of Portland Bureau of Planning and Sustainability. February 2, 2015. https://www.ecolloyd.org/lloyd-district-map/

Mackin, Bob. "The Olympic Village Developer Is Bankrupt." The Tyee. April 05, 2014. Accessed March 21, 2019. https://thetyee.ca/News/2014/04/05/Olympic-Village-Developer-Bankrupt/.

Map of Southeast False Creek (SEFC) and the Olympic Village. Lisa M Westerhoff. 2016. https://journals.openedition.org/articulo/2974

Metro Vancouver. “Appendix A Regional Context Statements.” Revised 2015. Accessed April 7, 2019. http://www.metrovancouver.org/services/regional-planning/PlanningPublications/TableA1-PopDwelUnit EmpProjforMVSubregMuni.pdf

Metro Vancouver Convention and Visitors Bureau. "Vancouver Awards and Accolades." Tourism Vancouver. Accessed April 10, 2019.

www.tourismvancouver.com/media/corporate-communications/vancouvers-awards-and-accolades/

National League of Cities. "Urban Infill and Brownfields Redevelopment." March 7, 2017. Accessed May 11, 2019. https://www.nlc.org/resource/urban-infill-brownfields-redevelopment

Nfaziol. "Millennium Water, Vancouver BC." Urban Ecology | CMU SoA. December 02, 2015. Accessed March 12, 2019.

https:/urbanecologycmu.wordpress.com/2015/11/17/millennium-water-vancouver-bc/.

Sisolak, Joel. PLUS Committee Approves EcoDistrict Resolution. Capitol Hill EcoDistrict. January 24, 2015. Accessed April 22, 2019.

http:/capitolhillecodistrict.org/plus-committee-approves-ecodistrict-resolution/

Statistics Canada. "2016 Census Profile of Vancouver, British Columbia and Canada." Statistics Canada Catalogue no. 98-316-X2016001. Ottawa. Released November 29, 2017. Accessed May 11, 2019. https://www12.statcan.gc.ca/census-recensement/2016/dp-pd/prof/index.cfm?Lang=E 
United Nations. "Report of the World Commission on Environment and Development: Our Common Future.” June 2015. Accessed May 18, 2019. http://www.un-documents.net/wced-ocf.htm

United Nations. "Sustainable Cities and Communities." UN 2030 Sustainable Development Goals. 2015. Accessed May 18, 2019. https://www.un.org/sustainabledevelopment/cities/

United Nations. "World Economic and Social Survey 2013." United Nations Department of Economic and Social Affairs. 2013. Chapter 3. Pp 69.

https://www.un.org/en/development/desa/policy/wess/wess_current/wess2013/Chapter3.pdf

US Green Building Council. “About USGBC.” nd. Accessed May 10, 2019. https://new.usgbc.org/about

US Green Building Council. “LEED v.4 Neighborhood Development Guide.” Launched in July 2013. Accessed May 10, 2019. https://www.usgbc.org/guide/nd

Vancouver Magazine. "Neighborhoods: False Creek \& Olympic Village.” n.d. Accessed June 2, 2019.

Vancouver Olympic/Paralympic Village. Green Building Brain. Nd.

https://greenbuildingbrain.org/neighbourhoods/vancouver_olympic_paralympic_village

View from False Creek Olympic Village. City of Vancouver Board of Parks and Recreation. N.d.

Accessed May 1, 2019. https://vancouver.ca/parks-recreation-culture/false-creek-olympic-village.aspx

The Village on False Creek Promotional Rendering. Millennium Development Corporation.

2009. Vancouver's medal-worthy Olympic Village, one of the greenest neighborhoods

anywhere. Kaid Benfield. Smart Cities Dive.

https:/www.smartcitiesdive.com/ex/sustainablecitiescollective/vancouver's-medal-worthy-olym

pic-village-one-greenest-neighborhoods-anywhere/9082/

Westerhoff, Lisa. Emerging Narratives of a Sustainable Urban Neighbourhood: The Case of Vancouver's Olympic Village. Articulo - Journal of Urban Research. p. 18, 49 April 26, 2016. Accessed 15 May 2019. DOI : 10.4000/articulo.2974

Williams, Nathan and Kristin Kendle. Seattle's Capitol Hill Neighborhood. February 12, 2019.

TripSavvy. https://www.tripsavvy.com/seattles-capitol-hill-neighborhood-2965114 
Appendix A - Publicity Material and Mission Statements Table

\begin{tabular}{|c|c|}
\hline PRIMARY MISSION STATEMENT & SPECIFIC GOALS + OBJECTIVES \\
\hline \multirow{3}{*}{$\begin{array}{l}\text { CAPITOL HILL ECODISTRICT } \\
\text { Advancing Neighborhood } \\
\text { Sustainability }\end{array}$} & $\begin{array}{l}\text { CULTURE - Foster neighborhood identity through a well- } \\
\text { designed built environment and support of local arts \& artists }\end{array}$ \\
\hline & HEALTH - Promote human health and community wellbeing \\
\hline & $\begin{array}{l}\text { EQUITY - Ensure the fair distribution of benefits and burdens } \\
\text { of investment and development }\end{array}$ \\
\hline \multirow{2}{*}{$\begin{array}{l}\text { "A community-driven effort that } \\
\text { promotes a socially equitable, } \\
\text { environmentally resilient and } \\
\text { culturally vibrant neighborhood." }\end{array}$} & $\begin{array}{l}\text { TRANSPORTATION - Maximize opportunities for walking, } \\
\text { biking and transit use }\end{array}$ \\
\hline & $\begin{array}{l}\text { HABITAT - Enrich urban habitat within the EcoDistrict and } \\
\text { surrounding neighborhoods to promote biodiversity }\end{array}$ \\
\hline \multirow{3}{*}{$\begin{array}{l}\text { "A community-driven effort to make } \\
\text { our neighborhood a national model } \\
\text { for environmental sustainability and } \\
\text { community health." }\end{array}$} & $\begin{array}{l}\text { ENERGY - Reduce non-renewable energy use and } \\
\text { associated greenhouse gas emissions }\end{array}$ \\
\hline & $\begin{array}{l}\text { MATERIALS - Reduce the negative environmental impacts of } \\
\text { materials through conservation and diversion }\end{array}$ \\
\hline & $\begin{array}{l}\text { WATER - Conserve potable water; reduce black water } \\
\text { production and polluted runoff }\end{array}$ \\
\hline \multirow{4}{*}{$\begin{array}{l}\text { THE VILLAGE ON FALSE CREEK } \\
\text { LEED ND } \\
\text { "While maintaining heritage ties to } \\
\text { the past, SEFC is being planned as } \\
\text { a model sustainable development } \\
\text { based on environmental, social and } \\
\text { economic principles where people } \\
\text { will live, work, play, and learn." }\end{array}$} & $\begin{array}{l}\text { "...a world-class master-planned neighbourhood was } \\
\text { designed that aspired to the highest levels of livability, } \\
\text { ecological health and economic prosperity." } \\
\text { - Real Estate Agency selling the units in The Village. }\end{array}$ \\
\hline & $\begin{array}{l}\text { "Southeast False Creek has gone from being a maligned } \\
\text { ghost town after the Olympics to becoming a culturally rich, } \\
\text { vibrant and sought-after neighbourhood, brimming with life, } \\
\text { amenities, and world-class real estate opportunities." } \\
\text { - from the Realtor Company selling the units in The Village. }\end{array}$ \\
\hline & $\begin{array}{l}\text { Create 'a neighbourhood which is integrated with its urban } \\
\text { context while protecting and enhancing the social and } \\
\text { economic health of its community as well as the health of } \\
\text { local and global ecosystems' } \\
\quad \text { - City of Vancouver, } 1990\end{array}$ \\
\hline & $\begin{array}{l}\text { Social Benefits: } \\
\text { - Increased community connection to the environment } \\
\text { - } \text { Park and community spaces } \\
\text { - Increased community capital }\end{array}$ \\
\hline
\end{tabular}




\section{Appendix B - Composite Timeline of Case Study Development}

- 2000: Sweden pioneers district-scale S.U.D. in Stockholm and Malmo.

- 2004: City of Portland and area business leaders commission an initiative to regenerate a 30-block district in Lloyd using principles of ecological design and economics.

- 2009: PoSI(Portland Sustainability Institute) kicks off the first conference dedicated to neighborhood sustainability at PSU for urban + community development practitioners.

- 2010: 70+ professionals gather to design the first EcoDistricts Protocol + Framework

- 2010: Vancouver Olympic Village Opens, achieving LEED Platinum for Neighborhood Development: "The award-winning Olympic Village in Vancouver's SE False Creek prototypes an ambitious environmental and social agenda. Rob Bennett and Tom Osdoba's participation in the project inspires them to found EcoDistricts"(Lloyd EcoDistrict, 2018, p. 4).

- 2011: USA's First EcoDistrict is Launched: Lloyd EcoDistrict in Portland. Their vision: Become the most sustainable neighborhood in North America.

- The Bullitt Foundation provides sustainable leadership in the Capitol Hill neighborhood through the pursuit of the "Living Building Challenge" (GGLO, 2012, p. v).

- The Federal Sustainable Communities program inspired Capitol Hill Housing, a Public Development Authority and Community Development Corporation, to more explicitly connect affordable housing with transportation access and the environment(GGLO, 2012, p. v). "The federal Sustainable Communities program (a collaboration between the U.S. Department of Housing and Urban Development, the U.S. Department of Transportation, and the U.S. Environmental Protection Agency) and the Puget Sound Regional Council's Growing Transit Communities that it funds inspired Capitol Hill Housing to more explicitly connect affordable housing work with transportation access and the environment."

- March 2011: The Bullitt Foundation awarded Capitol Hill Housing a grant to spearhead the creation of a new "EcoDistrict" on Capitol Hill, allowing them to work with GGLO to conduct the research and outreach efforts detailed in the proposal report for the EcoDistrict.

- 2012: Seattle's Capitol Hill EcoDistrict Founded: "Capitol Hill Housing, a Seattle-based community development corporation that serves the most densely populated urban village in the Pacific Northwest, launches the first official ecodistrict outside of Portland"(GGLO, 2012, p. 5).

- 2012: EcoDistricts Incubator is launched to help neighborhood project teams develop their own sustainability roadmaps.

- 2013: EcoDistricts is officially founded by Rob Bennett, Teague Douglas and JR Ralston with support from Kresge and Bullitt Foundations and the private sector.

- 2015: EcoDistricts begins travelling globally to promote District-Scale Sustainability

- 2016: Version 1 of EcoDistricts Protocol is published as an open-source document online

- 2017: Twelve projects have so far committed to get EcoDistrict certified 
Appendix C - GGLO Community Assets Map of Capitol Hill EcoDistrict
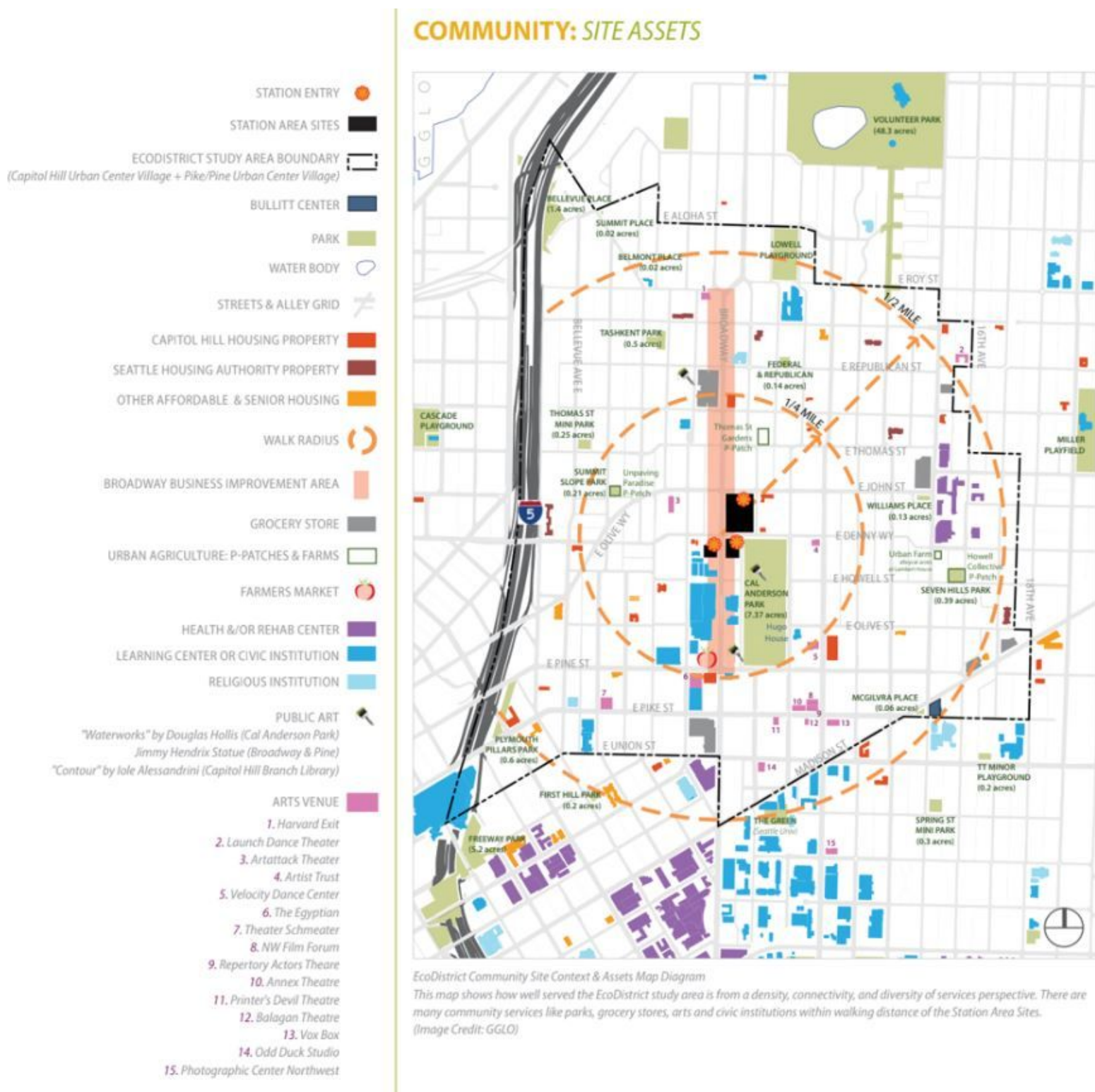

EcoDistrict Community Site Contert \& Assets Mop Diogram

This map shows how well served the EcoDistrict study area is from a density, connectivity, and diversity of services perspective There are many community services like paris, grocery stores, arts and civic institutions within waiking distance of the Station Area Site. (image (redit: GGLO) 